\title{
Options to design more ethical and still successful default nudges: a review and recommendations
}

\author{
Dominic Lemken \\ Department of Agricultural Economics and Rural Development, University of Göttingen, Göttingen, \\ Germany \\ E-mail: dlemken@gwdg.de
}

(Received 3 December 2020; revised 21 September 2021; accepted 5 October 2021)

\begin{abstract}
On the one hand, default nudges are proven to strongly influence behavior. On the other hand, a number of consumer autonomy and welfare concerns have been raised that hinder public policy applications. Both nudge success and ethical concerns depend heavily on the design of defaults. We identify six taxonomic characteristics that matter to the ethical and the nudge success dimension. We review the default nudge literature $(N=61)$ and review ethical studies to assess both dimensions concerning the taxonomy. When designing a default, a choice architect inevitably makes a decision concerning the characteristics. Among others, the results show three main findings. (1) The initial choice architecture regularly imposes welfare losses and impedes consumer autonomy. Forced active choosing can mitigate both issues. (2) Empirical evidence suggests that transparent defaults are similarly effective as the non-transparent counterparts. (3) The framing of the choice in combination with a choice structuring default leads to greater nudge success and tends to involve the reflective decision-making patterns. Choice architects can trade-off nudge success for legitimacy but a design change may also benefit one without harming the other. We discuss further options of choice architects to legitimize a default.
\end{abstract}

Keywords: opt-out; opt-in; consumer welfare; status quo; consumer autonomy

\section{Introduction}

Defaults nudges $^{1}$ are increasingly applied in behavioral domains. They can influence how much a person is willing to donate for a social cause, the food he or she chooses, the health care plan, whether a person opts for green energy, and more (Sunstein, 2015a, 2015b; Sunstein \& Reisch, 2019). Default settings determine the way consumers initially encounter the products, services, or policies (Johnson et al., 2012). The default setting may preselect a health care plan. Individuals are asked to sign

\footnotetext{
${ }^{1}$ Default nudges are referred to as 'defaults' throughout the article.

(c) The Author(s), 2021. Published by Cambridge University Press. This is an Open Access article, distributed under the terms of the Creative Commons Attribution licence (http://creativecommons.org/licenses/by/4.0/), which permits unrestricted re-use, distribution and reproduction, provided the original article is properly cited.
} 
the defaulted plan or are automatically enrolled in the plan unless they take action to refuse it. Generally speaking, default options influence behavior because people tend to continue with preset options (Von Bergen \& Miles, 2015). Naturally, there is more to be learned about the persuasion power of defaults.

On the one hand, there is substantial scientific evidence on default applications. Systematic reviews by Hummel and Maedche (2019) and by Beshears and Kosowsky (2020) find larger effect sizes for defaults than for any other nudge type. On average, defaults seem to be the most effective nudging tool in the box (Johnson et al., 2012). On the other hand, defaults are extremely versatile. Defaults group a simple preselection of an electronic checkbox, for example, on a food delivery website, in the same category as new legislation that registers every citizen as a potential organ donor unless actively refused. The average default is little representative of what constitutes a default. We will discuss how meta-reviews have only investigated very few characteristics of defaults and more is to be learned about the characteristics already discussed.

To date, there is substantial resistance to defaults in the policy arena, especially since ethical concerns have been raised. Defaults have been labeled 'hidden persuaders' (Smith et al., 2013). Critics have built cases with defaults why nudges threaten consumer autonomy and consumer welfare (Bovens, 2009; Heilmann, 2014). In return, nudging theorists have become more specific about the ethical implications in consideration of default characteristics. Such theoretical work implies several characteristics that change the legitimacy of a default (Goldstein et al., 2008; Hansen \& Jespersen, 2013; Smith et al., 2013; Sunstein, 2013, 2015a, 2015b; Sunstein \& Reisch, 2014; Loewenstein et al., 2015; Von Bergen \& Miles, 2015; Schubert, 2017; Mills, 2020; Fracassi \& Magnuson, 2021).

We focus on six characteristics that are related to the way the default is set up. We ignore the behavioral change demanded. Other reviews have made attempts to better understand nudging through the behavior asked of individuals (Michie et al., 2011; Löfgren \& Nordblom, 2020), which is relevant but often choice architects cannot alter the goal of an intervention. Although a number of taxonomic characteristics have been theorized on how to design a nudge (e.g., Hansen \& Jespersen, 2013; Münscher et al., 2016), the characteristics we propose apply particularly to default type interventions. The characteristics are all relevant to ethical assessments: (1) the initial state of the choice architecture, (2) the invasiveness, (3) the psychological effect mechanism, (4) the visibility of the decision, (5) the customization, and (6) the disclosure of the intent (Figure 1).

It is worth summarizing and reflecting on how design changes concerning the characteristics will affect legitimacy. Choice architects, consciously or unconsciously, decide on how to design defaults concerning these characteristics.

From the perspective of choice architects, the question arises whether design changes driven by the need to legitimize a default lessens the effectiveness of the very default. Meta-reviews have shown how defaults in the field are similarly effective to the ones in the lab (Jachimowicz et al., 2019), how triggering system 1, as defined by Kahneman, results in larger effects than triggering system 2 (Beshears \& Kosowsky, 2020) or how the effect size depends on the domain the default is applied in (Jachimowicz et al., 2019; Beshears \& Kosowsky, 2020). However, characteristics 

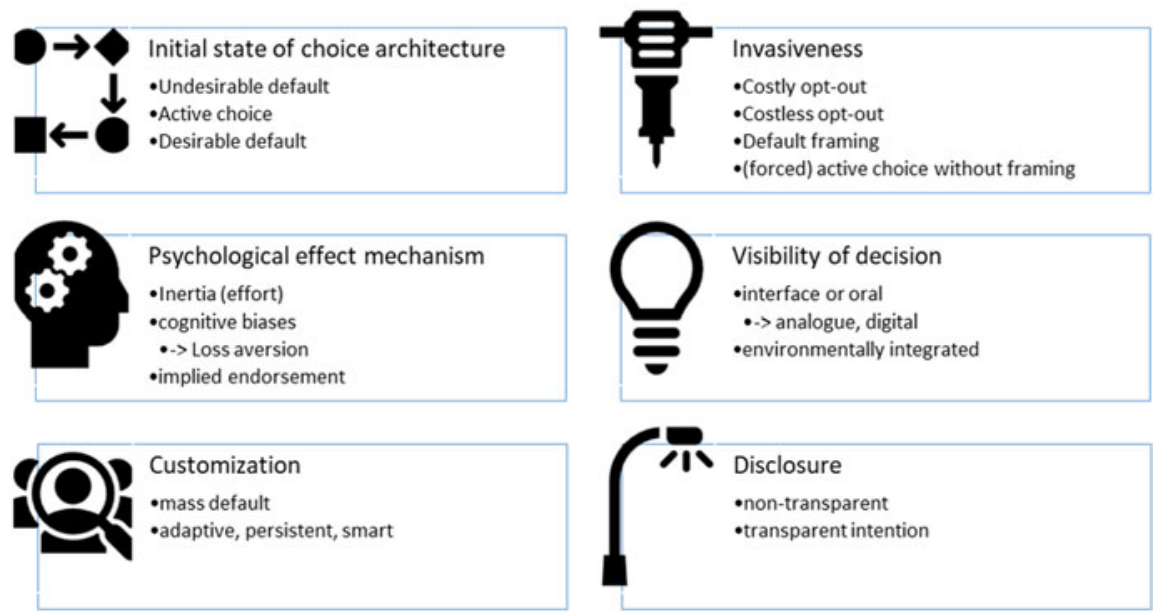

Figure 1. Taxonomic characteristics of defaults.

with strong implications for the ethical dimension of defaults have hardly been empirically researched. The effect mechanism (Section 'The psychological effect mechanism of defaults') exploited by defaults has been investigated (Jachimowicz et al., 2019), but the authors advise a cautious interpretation. The default literature had not investigated the effect mechanism and an ex-post analysis has noteworthy imperfections. Effect mechanisms of specific defaults should be further investigated (Zlatev et al., 2017). The automaticity trait often embedded in defaults, that is, the assumption of a choice in the absence of active decision making, can be shown to make a nudge particularly effective (Beshears \& Kosowsky, 2020). We will address this trait when we review the visibility of the decision.

The growing literature on defaults $(90 \%$ of the reviewed articles are published between 2015 and 2020) provides an opportunity to learn about the relevance of design characteristics. Conclusively, we review the default nudge literature. The review is presented as a narrative summary to demonstrate proof of the taxonomic concept. The empirical studies, although not one to one applicable when taken out of context, provide a priori information on how a design change can strengthen or weaken nudge success. Most importantly, this is the first study to summarize the empirical and ethical implications of these characteristics. The rationale of the review is to provide insights to further analyze the effectiveness of defaults, especially in terms of investigating ethically permissible defaults. Thereby, we answer whether choice architects have opportunities to ease ethical concerns or improve nudge success.

The article proceeds as follows. In the method section, we explain the concept of consumer autonomy and welfare. We also explain the narrative review of default's effectiveness. The results and discussion section elaborates on each taxonomic characteristic one by one. We synthesize the findings to show the general implications for policymakers and researchers. 


\section{Method}

\section{How to define default legitimacy}

Whether 'defaults do not force anyone to do anything ... (and) maintain freedom of choice' (Von Bergen \& Miles, 2015) depends very much on the design of defaults. Cherry Picking easily leads to defaults that violate nudging principles as defined by Thaler and Sunstein (2008). Two major objections to defaults are (1) consumer welfare losses and (2) the erosion of consumer autonomy (Smith et al., 2013; Sunstein, 2013, 2015a, 2015b; Sunstein \& Reisch, 2014; Schubert, 2017). (1) Firstly, the implementation of a purposeful default can, but need not, lead to an overall welfare gain for individuals. The expectation of an overall welfare gain has coined the term 'benign default' (Goldstein et al., 2008). An ex-ante cost-benefit analysis is advised to ensure a default improves decision-making (Sunstein \& Reisch, 2014).

Secondly, the heterogeneity of preferences leads to winners and losers of a policy change (Sunstein \& Reisch, 2014). A default may negatively affect vulnerable groups (Von Bergen \& Miles, 2015) or cause supply chain issues because supplier surplus is reduced. For example, in the German energy market, the basic supplier for each household is preset until a different contract has been signed (Kaiser et al., 2020). The introduction of a greener default contract may optimize overall welfare but can also burden some households with more expensive contracts that are not reflective of their environmental preferences.

(2) Consumer autonomy is an essential safeguard against non-benign defaults and preserves decision-making competencies if available. Nudging theory, including defaults, explicitly preserves the freedom of choice (Thaler \& Sunstein, 2008; Sunstein, 2013, 2015a, 2015b), that is, not limiting the options of consumers. In practice, a default may still lead to overlooking a better option, that otherwise might have been considered. Depending on the context, a default may also make a better option salient otherwise overlooked. The choice architecture upholds consumer autonomy if decision-makers are aware of their options, for example, all the energy contracts supplied in their region, and feel free to chose what they deem best (Vugts et al., 2020).

Besides the concept of freedom of choice, consumer autonomy sometimes accommodates an individual's capacity to deliberate and decide what to choose (Heilmann, 2014; Vugts et al., 2020). Choices add up and contribute to an individual's selfperception and identity (Vugts et al., 2020). When asked for a charitable donation, individuals are perceived as less intrinsically motivated if their choice was subject to a default (Wu \& Jin, 2020), which reduces a choice's contribution to identity. Similarly, donating organs is seen as more altruistic in countries in which citizens must opt-in to donate in contrast to opt-out regimes (Davidai et al., 2012). The design characteristics of choice architectures can grant different degrees of autonomy. We will explain how each characteristic changes the perspective on both consumer principles.

\section{The empirical literature review}

We tried to register the review with Joanna Briggs Institute and Prospero but were refused due to increased demand during the Corona pandemic. While the research objective of the review was not altered during the data collection stage, the taxonomic 
characteristics were refined during data collection. Not all design options concerning the characteristics were preconceived but are collected from the empirical literature.

The data collection stage adhered as closely as possible to the PRISMA Statement. We started a keyword search in two databases: the 'Webofknowledge' and 'Scopus'. The databases present relatively large abstract repositories available to the research team. To represent the diverse scientific fields that defaults are applied in, we did not restrict the search further to Author groups or specific Journals. This data set represents only a fraction of the research on default nudging but the systematic search process suggests that the data should not misrepresent the scientific literature in different fields.

The keyword search was refined by the wordings of previously identified 'default nudge' articles. Articles were considered if they use an expression for default and for nudging within the Abstract, Title, or Keywords. This includes studies that identify with the nudging literature and excludes a bulk of irrelevant studies that only use a default expression. The search string applies operators to account for different cases of relevant expressions: [('choice* architecture') OR (nudg*)] AND [(default ${ }^{*}$ ) OR (status quo) OR (opt* out) OR (opt $t^{\star}$ in)]. The search was limited to peerreviewed research articles, published in English after 2008, that is, after Thaler and Sunstein (2008) coined the term nudging. The eligible studies are empirical intervention studies of defaults that purposefully influence a behavior.

After removing duplicates, a senior researcher started to screen abstracts $(N=249)$. A bulk of studies were excluded because they dealt with defaults from an ethical or policy perspective or were commentaries but did not test an intervention. A few studies were qualitative or nudging reviews without primary data. In the Scopus search process, review articles were not automatically excluded but were manually removed during the screening process. Seventy-seven articles were fully read by four researchers, while two researchers collect the information of an article. A few more articles were excluded after discussion among the research team, although fully read. Reasons for exclusion were: (1) the default was essentially a ban of some options, depriving it of the nudge character, (2) the default was not intended to purposefully influence a behavior, (3) only the opinion on defaults was evaluated, but not the nudge effect, or (4) the implemented nudge represents a different nudging category as defined by Blumenthal-Barby and Burroughs (2012) rather than a default. The screening process is summarized in the following (Figure 2).

The included articles were reviewed by collecting study characteristics with respect to a PICO framework: population, intervention, control group, and outcome (behavioral change). We added entries on the timing of the study. The framework was a comprehensive collection of information strings, some of which were later numerically coded by the author and used within the review. The coded review protocol can be accessed via GitHub (https://github.com/dlemken/Default-Nudges). The main variables in the review protocol are: the number of tested defaults per study (sub-studies), the behavioral change demanded (target behavior), the behavioral domain (domain), the behavioral outcome conditional on the default type intervention (DDC), conditional on an active choice if available (ACC), conditional on a default type intervention opposing the interests of the choice architect (UDC), the unit thatthe behavior is measured in (unit), significance level as reported by the study (significance), the study type concerning lab or field studies (field_exp), and the taxonomy of the tested defaults (state of initial choice 


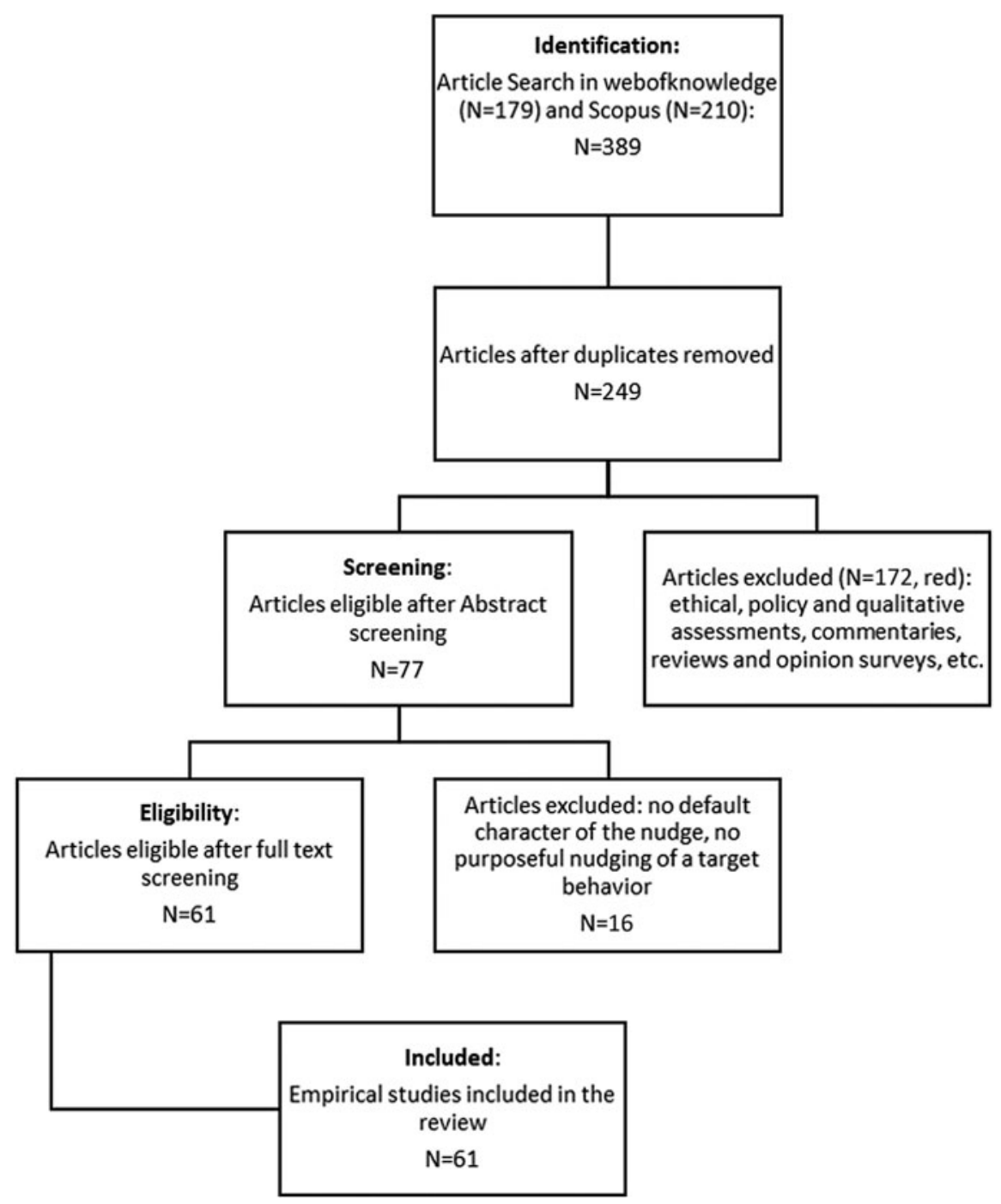

Figure 2. Literature screening - flow diagram. Data collection frame between January 2008 and April 2020.

architecture, invasiveness, visibility of decision, customization, disclosure). The Supplementary material also shares details on the study selection process, the quality assessment, and qualitative study descriptions. The results and discussion section will elaborate on findings from the review protocol regarding the taxonomic characteristics.

\section{Publication bias}

There is no reason to assume publication bias to vary systematically between the analyzed taxonomic characteristics of the studies, see also Beshears and Kosowsky 
(2020). For example, a comparison between customized and mass defaults should be on equal footing concerning publication bias. A minimum quality of the included studies is analyzed through a qualitative assessment of reporting characteristics, selection bias, and the internal- and external validity of the studies, according to a checklist by Downs and Black (1998).

\section{How to define default success}

We define nudge success as a two-by-one matrix: (1) behavior under status quo condition (control), and (2) under default condition. The narrative review presents both conditions. Significance tests between (1) and (2) are drawn from the studies at hand if available. The review focuses on default success within studies that vary the design of a taxonomic characteristic.

\section{Results and discussion}

The following sections will (1) explain the meaning of each characteristic and its features, (2) empirically compare the nudge success of features, particularly when multiple features experimentally vary within a study, and (3) discuss the ethical implications of a feature change. The features are best understood through each section. For the research community, we provide a full list of the reviewed empirical studies and the target behaviors they address (Appendix Table A1).

\section{a. The initial state of the choice architecture: Undesirable defaults, active choosing, and desirable defaults}

\section{Classification}

Each decision is subject to one of three states concerning defaults that we order by desirability in the eyes of the choice architect: Undesirable defaults (UDC) $\rightarrow$ active choice (ACC) $\rightarrow$ desirable defaults condition (DDC). Although an undesirable and a desirable default appear similar in nature, they promote conflicting target behaviors and differ substantially concerning nudge success. A DDC promotes a behavioral change desired by the choice architect. Vice versa, an UDC nudges toward a behavior that the choice architect opposes. ACC is characterized by a nudge that presents choice options on an equal footing, that is, individuals are exposed to a specific choice set but with a neutral presentation of all options (Table 1).

\section{Empirical findings}

The differences between UDC, ACC, and DDC are well illustrated in studies that evaluate all three states. Such studies hint at smaller differences between UDC and ACC than ACC and DDC (Supplementary Table A2). A shift from ACC to DDC is more likely to break habits and initiate a behavioral change. One reason might be the long-term effect of frequent exposure to UDC. A few studies show how a default effect can last (long-term effect) even if the initial conditions have been restored (Fosgaard \& Piovesan, 2015; Venema et al., 2018). Therefore, the defaults influence not only the choice at hand but also the underlying preference structure. 
Table 1. Summary: observations on the effect of the initial state of choice architecture on default success and legitimacy

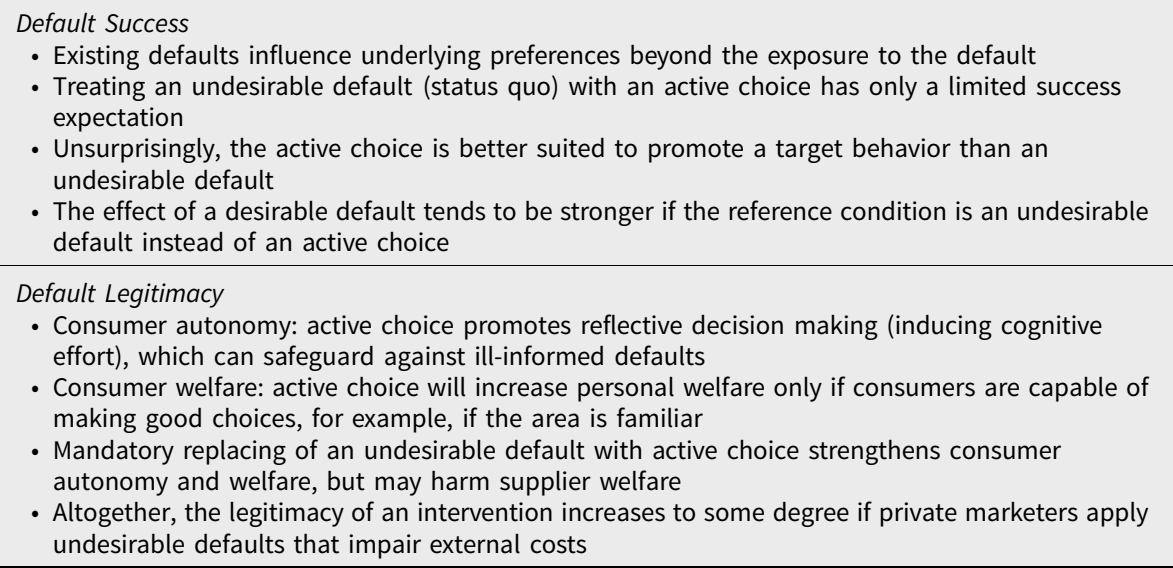

Taste preferences, such as for a thicker dessert, depend on the exposure to the taste and the habit of post-rationalizing a particular option. Here, we put forward an additional objection for ethical consideration. It is argued that, among other characteristics, the legitimacy of defaults depends on the majority endorsing the intervention (Engelen, 2019; Sunstein \& Reisch, 2019). As we can assume preferences to be biased by the initial choice architecture, we have to assume that public endorsement is even lower than the true preferences in case consumers have been exposed to UDC. In theory, DDC can grow more legitimate through the long-term exposure of individuals.

Nevertheless, a choice architect can prefer ACC over UDC. An exception is a charity study in the Gili Tarwangan region in Indonesia (Nelson et al., 2019; Supplementary Table A2, \#8). Tourists were asked whether they would contribute to an NGO with eco-conservation purposes in the region they visit. The active choice was a blank space where participants could enter the amount they were willing to contribute. The default conditions were structured such that the default was the proposal of a typical donation amount (10,000 Rupees). UDC and DDC only differed in the phrasing of the question, that is, the DDC asked whether they agree to donate the proposed amount, while the UDC asked whether they do not agree. Here, the effect of defaulting an amount guides decision-makers and describes the choice. The defaulting of an amount appears more relevant than the phrasing of the ask. Unfortunately, such details of how a default treatment is defined by researchers complicate a comparison across studies.

It is reasonable to assume that DDC is more effective if individuals are typically exposed to UDC in their daily life. When individuals make active choices on a matter, they start post-rationalizing the decision and are less likely to revisit. A complete meta-analysis might be able to address the latter across studies because ACC and UDC are common control groups and the control groups are often chosen in consideration of a status quo in real-life settings. However, the research domains and the target behaviors in this review differ widely. If we ignore all the shortcomings of a 
bivariate analysis, of relative effect sizes, and the different study contexts, then a Wilcoxon rank-sum test suggests a significantly stronger effect $(p=0.0014)$ of DDC if the control group was UDC and not ACC.

\section{Ethical implications}

Scholars have addressed the ethical implications of ACC and default choice architectures (Smith et al., 2013; Sunstein, 2013, 2015a, 2015b; Sunstein \& Reisch, 2014; Schubert, 2017). ACCs hold consumer autonomy advantages such as promoting reflective decision-making and safeguarding against ill-informed defaults (Sunstein \& Reisch, 2014). The consumer welfare perspective is less clear. The goal is to make people better off but if the area is unfamiliar, highly technical, or confusing, ACC might have the opposite effect (Sunstein \& Reisch, 2014; Sunstein, 2015a, 2015b). Active choice versus defaults is a vibrant part of the debate on whether policymakers should, in any circumstances, consider defaults.

The presence of a UDC in real-world choice architectures can impose significant welfare losses. For example, it is argued that replacing paper account statements from financial service providers with e-statements increases welfare. An investigation shows that a regime that automatically hands out paper statements unless actively opted-out (UDC) results in significantly more paper statements than other choice architectures (Theotokis \& Manganari, 2015). Both ACC and DDC can increase consumer participation in the e-statement service (Theotokis \& Manganari, 2015). The UDC is the status quo. A regime change to DDC may lead to consumers thinking that the e-statements have been inflicted on them without providing a proper choice, possibly even selecting them into a choice they do not want. While such concerns depend on the design of DDC, it cannot be argued that ACC deprives consumers of the autonomy to choose. Defendants of the status quo will find it harder to oppose the implementation of ACC. The same arguments that have been used to defend the status quo (UDC) can now be applied in favor of an intervention. For example, objections on consumer autonomy and how defaults may degrade an individual's ability to cope with decision tasks in the long run (Smith et al., 2013; Sunstein, 2013; Schubert, 2017). The mandatory ACC provides policymakers with an additional option to act.

A policy intervention targeting choice architectures interferes with a company's right to choose a choice architecture, but significant consumer welfare losses induced by the very choice architecture may outweigh such claims. In a brief sentence, Smith et al. (2013) argued that the legitimacy of a (desirable) default increases when policy nudges compete with counter-nudges from private marketers.

\section{b. Invasiveness of defaults}

\section{Classification}

The invasiveness of a default can be categorized into four basic default categories: (1) defaults with costly opt-out, (2) defaults with a costless opt-out, (3) active choice with default framing, and (4) active choice without framing (Sunstein \& Reisch, 2014, 2016). We registered defaults as 'costly opt-out' if the execution (not the decisionmaking process) to opt-out exceeds one minute, the equivalent of $1 €$, or was not feasible for everybody. In case the opting out was not costly, the default is registered as 
Table 2. Summary: observations on the effect of invasiveness on default success and legitimacy

Default Success

- Costly opt-outs make defaults clearly stickier than regular (costless opt-out) ones

- Forced active choice nudges have a consistent but moderate effect on behavior

- Default framing and regular defaults can outperform each other. Depending on the capacity for cognitive processing, the setting, and the target population, one might be more suited than the other

- The combination of framing and regular defaults is more successful than the single use of one

Default Legitimacy

- Consumer autonomy: default frames are more likely to trigger deliberation and reflective decisions

- Regularly, active choice with default framing is not applicable due to limited cognitive capabilities to process information or technical impossibilities to design an active choice

- Costly opt-outs are not compatible with nudging theory and should not be labeled as such

- Consumer welfare: costly opt-outs in undesirable defaults can be particularly welfare threatening and should be identified as such

'costless opt-out'. Default framing refers to active choice while a frame highlights one option to be the status quo or usual option. Framing does not structure the choice task but describes it. The frame addresses how a specific option is recommended or typically selected which implies social desirability. In consumer research, the framing of an active choice has also been labeled 'enhanced active choice' (Keller et al., 2011). Active choice without framing presents an additional treatment option to an undesirable default that has a nudge but not a default character (Sunstein, 2015a, 2015b). The choice is overly salient to individuals and individuals cannot ignore it and continue a habit without explicit decision-making. In theory, the invasiveness declines from 1 to 4 (Table 2).

\section{Empirical findings}

Costless opt-outs (2) are what behavioral researchers commonly understand as a default. A particular choice is preset which makes it the easiest option but opting out is only a matter of decision-making action. The majority of empirical literature tests this default (48 out of 61). In the following, we refer to a costless opt-out as the regular default.

Costly opt-outs (1) are limited to four studies in this review (Brune et al., 2017; Loeb et al., 2018; Briscese, 2019; Ghesla et al., 2019). In field experiments, individuals had to $\log$ in to a web account to find and change a financial decision (Briscese, 2019) or parents had to call to deselect a lunch menu for their kids (Loeb et al., 2018). Both report large effects from 5 to 78 and from $0 \%$ to $98 \%$. Only a lab experiment allows for a 1 to 1 comparison between a default costly in one and costless in a different treatment (Ghesla et al., 2019). Individuals had to solve small puzzles to deselect a preselected donation amount. In this case, 59\% of individuals accepted the default and donated their maximum endowment, while only $34 \%$ did so when a costless optout was offered. A costly opt-out will undeniably be a stickier default than a regular one (Sunstein \& Reisch, 2014).

(Forced) Active choice without framing (4) is typically a forced choice in experiments. Defaults and forced ACC should not be confused. For example, experimenters have handed out preselected food menus to kids, but the study procedure asked kids 
to reevaluate and confirm the choice after $10 \mathrm{~min}$ (Wansink \& Just, 2016), thereby forcing an active choice and diluting the claimed default character. Generally, DDCs are feasible if UDCs exist, but a couple of studies have decided to only treat a UDC with a forced ACC (Hoffmann et al., 2019; Kesternich et al., 2019; Patel et al., 2016, 2017). An example is a voluntary contribution to a carbon offset program (8 Euro-Cents per kilometer) when purchasing a bus ticket (Kesternich et al., 2019). In the UDC, individuals can ignore the box for participation in the program, which is initially deselected. The forced ACC obliges individuals to make this decision, thereby requiring a conscious decision for or against the contribution, which is intended to trigger guilt if opting out. The share of individuals willing to contribute increased from $17.7 \%$ to $26.5 \%$. The other mentioned studies with forced active choice treatments report similar effect sizes, all of which are reported to be significantly different from the control group.

Default framing (3) is either exclusively applied or in combination with regular defaults. For example, several studies have promoted food choices in a restaurant with a 'dish of the day' frame (Bergeron et al., 2019; Saulais et al., 2019), implying a default option. When only the framing is applied, the choice for the 'dish of the day' increases from $34.4 \%$ to $59.6 \%$ with some variation depending on dish popularity, setting, and the number of dishes framed (Saulais et al., 2019).

A few studies apply defaults and default frames in separate treatments and allow for a comparison (d'Adda et al., 2017; O’Reilly-Shah et al., 2018; Nelson et al., 2019; Schneider et al., 2019). The results point to similar nudge success. Frames and regular defaults can outperform each other depending on the context. Scenarios that are highly suited to involve reflective decision-making can benefit from frames and forced active choices. Frames and regular defaults have heterogeneous effects, persuading different types of individuals. A systematic review of interventions on healthy food choices shows how choice structuring interventions have been found to narrow the inequality in food choices along socio-economic characteristics while providing information or education, similar to framing, tends to widen the gap (McGill et al., 2015). Therefore, the choice for framing or choice structuring defaults will probably depend on what type of group is to be nudged.

However, frames and regular defaults complement each other. The frame describes the choice and the default structures, thereby addressing automatic and cognitive elements of decision-making. In fact, many researchers have complemented their default by a default frame, usually referring to the whole intervention as one default (Momsen \& Stoerk, 2014; Dogruel et al., 2017; Fonseca \& Grimshaw, 2017; van Kleef et al., 2018; Arvanitis et al., 2019; Schneider et al., 2019). All of the reviewed combined interventions significantly influence behavior as intended by the choice architect.

Two of the studies show particularly well how the combination of both improves nudge success. Firstly, in a healthcare setting, compliance with updated recommendations for mechanical ventilator settings was researched (O'Reilly-Shah et al., 2018). The regular default changed the default settings of the ventilator machines so that physicians had to actively reset them if they wish so. The default frame was a quarterly email reminder showing each physician's ventilator compliance compared to the average compliance rate of the entire clinic. These treatments were compared to an 
UDC without emails and non-optimal ventilator settings. Here, only the default frame significantly changed the outcome, raising the compliance rate from $59.3 \%$ to $75.5 \%$. A combination of both defaults led to a compliance rate of $87.8 \%$.

Secondly, an experiment evaluated individuals' openness to select an electronic identification card (eID) in a mock governmental webpage setting (Schneider et al., 2019). The combined webpage's preselection of an eID and a default frame stating that ' $77 \%$ opted for an eID' convinced $87 \%$. If only one of the treatments was used, $74 \%$ and $76 \%$ select an eID. In an ACC, $46 \%$ select the eID.

\section{Ethical Implications}

Defaults with costless opt-out (2) influence particularly system 1 decision making. The structuring of the choice task intends to guide automated or intuitive decisions. In contrast, decision framing is more likely to influence system 2, because consumers are asked to reflect on a description of the choice. If nudges entail the risk of bypassing the reflective system, they are often perceived as paternalistic (Heilmann, 2014; Schubert, 2017). Consistent with such reservations, citizens perceive nudges targeting system 1 decision-making as more autonomy threatening than other nudges (Jung \& Mellers, 2016). If a choice is characterized by reflective decision-making, then a choice structuring default does not seem appropriate. The combination of default with frames helps to reflect on the default option and make it simpler to choose. For example, physicians can be exposed to default ventilator settings and an email on what settings should be selected (O'Reilly-Shah et al., 2018).

Default framing (3) raises the salience of an option. From a theoretical point of view, the ACC (discussed in the previous section) and default framing preserves consumer autonomy (Smith et al., 2013). The ACC demands individuals to take their well-being into their own hands and decide what is good for them. The default frame, if truthfully specified, informs decision-making.

However, in many instances, a default frame is not applicable or even not feasible. Firstly, the sheer number of choice tasks and limited cognitive capacity hinder the full comprehension of all choice tasks in daily lives. For example, individuals face over 200 food choices each day (Wansink \& Sobal, 2007). Understandably, individuals have developed heuristics to deal with the bulk of choices to manage information overload. Often enough, the stakes are not high in singular decisions but quickly sum up to meaningful health effects. Furthermore, each decision may come with an overwhelming number of options. From a consumer welfare perspective, a regular default is preferable to active choosing if the decision is complex for non-experts (Sunstein, 2015a, 2015b). Nevertheless, active choosing, especially with framed decisions, will also improve consumer welfare relative to UDCs.

Defaults with a costly opt-out (1) are not common in the scientific literature, but this may not hold for the real world. Such defaults should not be labeled as nudges. They violate nudging theory and can hold properties similar to a ban. In some instances, individuals may not have the resources to opt-out. Choice architects are advised to not label them as nudges so that theoretical work and ethical assessments focus on nudging properties. Nevertheless, costly opt-outs are less welfare threatening than a ban and are therefore easier to legitimize (Sunstein \& Reisch, 2014, 2016). 
Table 3. Summary: observations on the effect of the psychological mechanism on default success and legitimacy

Default Success

- The reviewed studies do not assess the psychological mechanism employed

- In retrospect, a confident decision on the mechanism employed by a default is difficult, as the mechanisms are entangled and weigh differently in each scenario

Default Legitimacy

- Consumer autonomy: Relying on inertia to influence individuals is compatible with autonomy if it is understood that opting out is possible

- Consumer welfare: Relying on implicit endorsement can convince individuals to select a default that is not in their best interest if individuals are unfamiliar with the behavioral area

- The exploitation of cognitive biases adversely affects consumer autonomy and welfare

- Potentially, nudges can be designed to help overcome cognitive biases

- Advisably, choice architects study the psychological effect mechanism of defaults at hand

However, the low legitimacy of costly opt-out does also apply to costly UDCs. The example where parents need to call to deselect an unhealthy lunch menu for their kids shows how $100 \%$ of parents followed the UDC, while $98 \%$ followed the reversed default (Loeb et al., 2018). Neither the UDC nor the DDC with costly opt-out is likely to reflect the underlying preferences. The UDC choice architecture causes preventable welfare losses that help to legitimize an intervention. This intervention must not be a full reversal, that is, not a DDC with costly opt-out.

\section{c. The psychological effect mechanism of defaults}

\section{Classification}

Although the naming of concepts differs between researchers, there are three main psychological mechanisms theorized of how a default influences behavior: (1) inertia, (2) implied endorsement, and (3) cognitive biases (Smith et al., 2013; Sunstein \& Reisch, 2014; Von Bergen \& Miles, 2015; Münscher et al., 2016; Ghesla, 2017; Schubert, 2017; Jachimowicz et al., 2019; Paunov et al., 2019). (1) Decision-making requires cognitive effort. The rejection of a default requires active steps to opt-out. Depending on preferences, individuals might be reluctant to make the effort or invest the thought (cognitive cost) (Smith et al., 2013; Ghesla, 2017). (2) The preselection of an option can signal a recommendation by the choice architect (McKenzie et al., 2006). Some individuals might also interpret the preselected option as the one the majority endorses (Smith et al., 2013) which adds a social norm nudge trait nested in the default. This trait can exist for choice describing and choice structuring defaults. (3) Individuals may also use biased decision-making strategies, such as an irrational preference for the status quo (Momsen \& Stoerk, 2014; Paunov et al., 2019). They may perceive the default option as an endowment and act according to loss aversion biases (Table 3).

\section{Empirical findings}

The reviewed studies do not control for the effect mechanism. One exception is a study that investigates how loss aversion interacts with a default (Stryja \& Satzger, 2019). Here, a set of investment decisions is applied to identify loss aversion. 
Then, individuals select a rental car for a business trip. In the first round, only one electric and one diesel car are offered. In the second round, the choice set consists of three diesel and three electric cars. In the second round, one experimental variation introduces a default that preselects individuals to choose the electric car with the medium price and medium power. Under an ACC, 3.3\% switch to an electric car after previously selecting a diesel. The DDC causes $11 \%$ to switch to an electric model. Individuals with a higher loss aversion are less often swayed by the default, though no significant relationship is observed (Stryja \& Satzger, 2019). Therefore, the case study does not introduce a default that exploits loss aversion.

Although we attempted to categorize defaults based on the mechanism employed, we could not make a confident decision. All three mechanisms are entangled and weigh differently in each scenario. Lab experiments with readily available choice sets are less characterized by inertia than field experiments where decision-makers have to decide to deal with a decision task, possibly starting an evaluation of alternatives and only then exercise a choice. Conclusively, we support the call for research into the effect mechanism (Zlatev et al., 2017; Szaszi et al., 2018). Currently, choice architects seem to naturally anticipate the effect mechanism without empirical confirmation (Zlatev et al., 2017). New ideas and opportunities will follow from empirical research.

\section{Ethical Implications}

The identification of the psychological mechanism may explain what makes defaults such a powerful force in shaping people's behavior (Schubert, 2017) and whether that force is ethically acceptable.

When Inertia (1) drives choices and individuals recognize the choices and understand that they can reject the default option, then autonomy is maintained (Smith et al., 2013). A nudge relying on inertia will be rejected if individuals hold strong preferences against it, which makes such a default hardly welfare threatening. Individuals shy away from the effort, particularly the cognitive costs, to switch because they are willing to accept an outcome over actively choosing a slightly better one.

Implied endorsement (2) can mislead individuals to believe that the default option is carefully chosen for their needs (Smith et al., 2013). The implied endorsement resembles social norm nudges and has to uphold similar ethical considerations. Individuals may reject the social norm because they are confident about their decision. It can be shown that defaults cannot steer behavior when the nudged individuals are experts in the matter (Löfgren et al., 2012). A knowledgeable consumer, the ideal case for ACC, is expected not to change their behavior, but less knowledgeable ones may suffer welfare losses as they may believe in an endorsement despite not being in their best interest.

Cognitive biases (3) can be an underlying cause of a default's effectiveness. As a policy instrument, the exploitation of biases inevitably degrades consumers' autonomy (Smith et al., 2013). Individuals are no longer able to fully understand the options. The freedom of choice is not preserved. Additionally, welfarists' concerns loom larger if the default relies heavily on cognitive biases (Smith et al., 2013). The choice architect uses a flawed understanding of options to promote an agenda. Consumers may not act in their best interest. In theory, a nudge can be designed 
Table 4. Summary: observations on the effect of visibility of the decision on default success and legitimacy

Default Success

- Generally, environmentally integrated defaults purposefully influence choices

- It is context-dependent whether environmentally integrated or defaults visible on an interface is better suited to change behavior, for example, little cognitive capacity for a choice implies an environmentally integrated approach

Default Legitimacy

- Consumer autonomy: environmentally integrated defaults can lead to a non-reflection of a choice, especially if the choice occurs infrequently

- Ideally, environmentally integrated defaults simplify a better option without hiding alternatives. Advisably, awareness of the option to opt-out is controlled for

- Consumer autonomy: defaults presented on an interface typically demand an active confirmation which can involve reflective capacities

to help individuals to overcome biases that occur even in ACC scenarios and thereby maximize welfare. For example, framed nudges may inform individuals about a commonly observed decision bias in the task at hand. Conclusively, a study that can show how cognitive biases are not the cause of the default's effect or are proven to reduce existing cognitive biases, can strengthen the ethical evaluation.

\section{d. Visibility of decision}

\section{Classification}

Here, visibility refers to how easy it is for individuals to notice a decision at hand (Hansen \& Jespersen, 2013). Recognizing a choice comes with the awareness that opting out is a possibility, that is, noticing that alternatives exist. We distinguish two types of defaults concerning visibility: (1) defaults that appear on some kind of digital or conventional interface and (2) environmentally integrated defaults. Although previous research has not explicitly categorized defaults depending on this feature, it should not be overlooked when assessing the ethical dimension of defaults (Table 4).

(1) An interface formally presents the choice and explicitly states the preselection made by the choice architect. The choice is displayed on paper, posters, flyers, boards, electronic screens, or might be orally communicated. For nudge success, a digital interface may differ from an analog one (Hummel \& Maedche, 2019; Jachimowicz et al., 2019) which does not necessarily change visibility.

(2) An environmentally integrated default rule is implemented in the physical environment surrounding a specific behavior. It can be a change to the means to perform a behavior or a change to the procedure of a choice. Such environmentally integrated defaults do not explicitly state the choice, therefore can be less visible.

\section{Empirical findings}

The reviewed studies do not compare environmentally integrated defaults with those that are made visible on some kind of interface. Some studies ( 9 out of 61) test environmentally integrated defaults (Liebig \& Rommel, 2014; Shealy \& Klotz, 2015; 
Bourdeaux et al., 2016; Brune et al., 2017; Friis et al., 2017; Mikkelsen \& Romani, 2017; O’Reilly-Shah et al., 2018; Shealy et al., 2018; Venema et al., 2018). Most of them report significant effects (Supplementary Table A4).

Many of these entail changing the means of behavior. For example, the elevation of stand-up work desks at a governmental facility in the morning led to an average standing time per employee of $13.1 \%$ during working hours as opposed to $1.8 \%$ before the intervention (Supplementary Table A4, \#47). Environmentally integrated defaults in food buffets tend to change the default procedure of selecting an option (Friis et al., 2017; Mikkelsen \& Romani, 2017). For example, a food buffet that offers butter versus a food buffet where butter can only be requested through an available staff member. The procedural change led to 0.3 butter packages consumed per person as opposed to 0.7 (Supplementary Table A4, \#25).

The environmental changes go hand in hand with an automaticity trait. Individuals are automatically selected into a behavior if they do not adapt their behavior. They will have to start standing at work (\#47) or will no longer consume butter (\#25) if they chose to 'not act'. Although the automaticity trait is feasible for choices that occur on an interface, this is not a regular trait of such defaults. When a choice on an interface is ignored, choice architects can determine an automatic choice (Momsen \& Stoerk, 2014). Choice architects may even set a clock to automatically determine a choice unless opted-out in time (Mazar \& Hawkins, 2015). When reviewed the automaticity trait has been shown to make nudges particularly effective (Beshears \& Kosowsky, 2020). However, we do not find evidence that environmentally integrated defaults are generally more effective. The reviewed studies apply either type without contrasting it. Ignoring the imperfections of a bivariate comparison, the relative effect size of the nine environmentally integrated studies is very similar to the average default success. A Wilcoxon rank-sum test attests no significant differences ( $\mathrm{p}$ $=0.8345)$. We advise a cautious interpretation. The context of the target behavior differs strongly across studies.

\section{Ethical Implications}

Environmentally integrated: Nested in the visibility of a decision is the discussion on how involved the reflective system should be in decision-making. Similar to default framing versus regular defaults, it is ethically preferable to involve the reflective system (Heilmann, 2014; Engelen, 2019). One prominent example is the case of policies on becoming an organ donor. While opt-out regulations create welfare for the citizens, as the regulation raises the number of donors, this comes at the costs of some citizens becoming a donor without ever consciously agreeing. The choice to become a donor is not visible to citizens (Hansen \& Jespersen, 2013) but presents a purely environmental change, that is, a change to the procedure of becoming a donor. Hansen and Jespersen (2013) refer to it as background default.

Recognizing the disregard of the reflective system, MacKay and Robinson (2016) argued for a mandated (forced) active choice, which we have previously discussed concerning ethical implications. In contrast, Whyte et al. (2012) argued from the perspective of close relatives that an opt-out system with veto options for the family is best suited to the real situations in health care. The organ donor debate has caused considerable confusion on defaults and can lead to premature rejections of defaults despite a less sensitive taxonomy. 
Table 5. Summary: observations on the effect of customization on default success and legitimacy

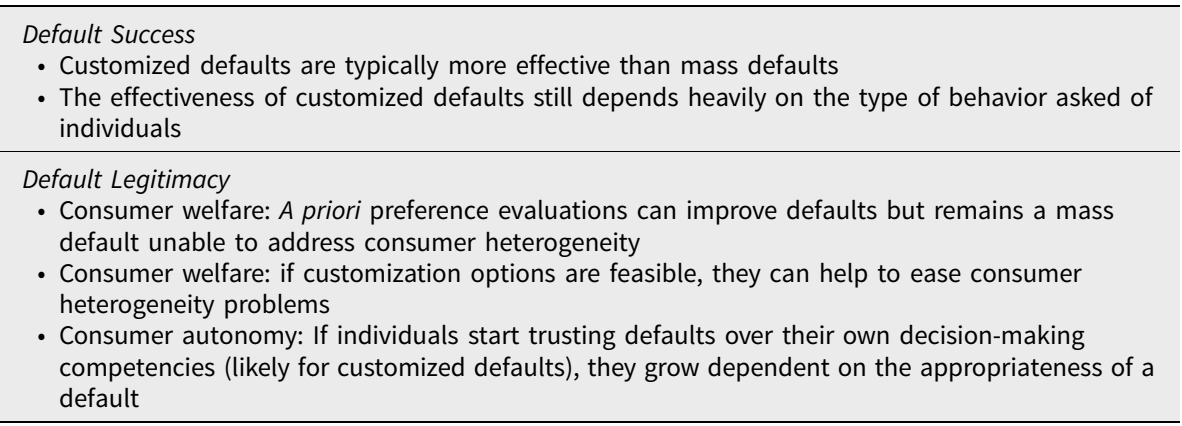

In practice, other environmental integrated changes to choice architectures have added to concern about defaults, for example, 'dark patterns' where user interfaces purposefully hide options through a series of preselections. Such environmental changes are not representative of defaults, in fact, they violate nudge properties as they actively undermine the freedom of choice (Reisch, 2020). We recommend a poststudy evaluation of the visibility of the decision. Ideally, an environmentally integrated default has simplified a better option without hiding alternatives.

The reviewed studies introduce rather frequent choices (Supplementary Table A4). Decision-makers are less likely to repeatedly act against their own interest, as they learn from the consequences of an automatic selection process. Thus, low visibility is especially problematic, if the choice does not occur frequently, since this makes it more likely to continuously bypass the reflective system.

Interface: Strictly speaking, most choice sets on an interface do not allow 'no active steps'. Individuals cannot ignore the choice. Individuals are required to confirm an option, for example, by signing a contract or through a mouse click. Defaults on interfaces involve some reflective capacities of decision-making. Definitions of 'defaults as settings that apply, or outcomes that stick, when individuals do not take active steps to change them' (Sunstein \& Reisch, 2014), may not fully accommodate default applications on an interface, as they typically demand this active step. The active step can also be seen as a safeguard for autonomy, as consumers are not automatically selected into a choice.

\section{e. Customization of defaults}

\section{Classification}

A categorization of customized defaults was proposed by Goldstein et al. (2008): (1) A 'mass default' treats all individuals equally. A mass default can be a benign evaluation of risks, utility, and costs, or a random selection because the setting demands a default rule. By definition, mass defaults are uniform between decision-makers. (2) A 'customized default' occurs in three forms. A persistent default preselects an option previously selected. A smart default considers characteristics of the population to make an educated guess on the preferred option. An adaptive default is dynamic and updates itself based on other (often real-time) choices observed of an individual. Customized defaults are also referred to as personalization (Johnson et al., 2012; Mills, 2020; Table 5). 


\section{Empirical evidence}

Customization is a niche in experimental studies (4 out of 61) (Probst et al., 2013; Goswami \& Urminsky, 2016; Camilleri et al., 2019; Hoffmann et al., 2019). In the context of retirement investments, smart defaults are applied to guide individuals toward better choices (Camilleri et al., 2019; Hoffmann et al., 2019). Smart refers to customization depending on age. Older individuals (here 51-60 years) are defaulted in a less risky conservative investment strategy, while younger ones (1825 years) are encouraged to select high growth and high-risk options in line with a life-cycle investment model. In the experiment, $60 \%$ follow such a smart default and $42 \%$ follow a generic default of a balanced option (a statistically significant difference). In a similar study, the default options for retirement funds are presented in line with the Australian superannuation choices. Once more the smart default is adjusted to the age in line with the life-cycle investment model, while the generic default preselects a balanced option. Given the authors' objective to promote socially responsible investment (SRI) funds, this specific smart default is counterproductive, because more individuals stick to the smart but non-SRI default. Under the smart UDC, $4.4 \%$ select a SRI fund, under a mass default $6.5 \%$, and the ACC 12.1\% (Hoffmann et al., 2019). For the better or worse, smart defaults are stickier than mass defaults (Probst et al., 2013; Camilleri et al., 2019; Hoffmann et al., 2019).

Goswami and Urminsky (2016) applied a persistent default to increase the share of charity donors. In many variations, a default was tested that preselects a charity amount sensitive to an individual's donation behavior within the last 2 years. There is no indication of the persistent default being particularly effective in this study. However, a sub-study introduces a different type of persistent default in the sense that individuals are defaulted to donate to organizations they have previously donated to, rather than donating to a pre-determined NGO. This sub-study finds a particularly high share of people willing to donate to their customized NGO. The amount to donate and the NGO recipient are both customizations of the target behavior but the latter is more relevant to potential donors in such experiments. Theoretically, choice architects cannot only adjust the target behavior in various ways but they may also change the design of the default. They may switch from default framing to a regular choice structuring default if information suggests this is better suited to the individual. Empirically, this has not been researched but has previously been described as delivery personalization (Mills, 2020).

\section{Ethical Implications}

Mass nudges: A few mass nudges build on a priori preference information. They use the information to preselect (food) options promising to change behavior when defaulted (Campbell-Arvai et al., 2012; van Kleef et al., 2018) or exclude individuals from the sample population that already implement the desired behavior (Liebig \& Rommel, 2014). In these cases, the default remains uniform for each individual, but the mass nudge is probably a more reasonable request. Using such information would help for ex-ante cost-benefit analysis and to design stickier defaults. It may even help to enhance public support for the implementation. However, a mass nudge is unable to solve some welfare objections, as explained below. 
Customized nudges: Welfare objections concern the heterogeneity in individual preferences (Smith et al., 2013; Sunstein, 2013; Sunstein \& Reisch, 2014; Mills, 2020). While a default will produce winners, others are nudged against their preferences and can end up with a utility loss. Possibly, lower education and lower-income go hand in hand with less confidence in decision making and therefore stickier default options independent of personal utility (Sunstein, 2013; Sunstein \& Reisch, 2014). After having finalized our data collection, a study was published that explicitly considers income differences when defaulting individuals into green energy contracts (Ghesla et al., 2020). An understanding of low-income groups helps to grasp welfare concerns for vulnerable consumers. Are they opting out and who is not opting out, despite opting out being in their best interest?

Customization can ease heterogeneity concerns (Sunstein, 2015a, 2015b; Mills, 2020). The empirical findings imply a reduction in opting-out. This customization also reduces the percentage of individuals adversely affected. Consumers will find it simpler to select the option suited to their needs (Thaler \& Tucker, 2013). The reviewed empirical examples, such as a default adjusted by age, will ease but not lead to a Pareto optimum and thereby leave some heterogeneity concerns on the table. Emerging opportunities with personal and big data will lead to better guesses, further mitigating the heterogeneity issue (Sunstein, 2013; Mills, 2020).

However, the data to optimize customizations is all too often sensitive to consumers (Sunstein, 2015a, 2015b; Fracassi \& Magnuson, 2021). Consider the banking sector where customer data is strongly protected. Restricting data sharing due to privacy concerns can manifest market inefficiency (Thaler \& Tucker, 2013) because options to help individuals to better products or better financial decisions are often limited to the institutions currently subscribed (Fracassi \& Magnuson, 2021). The sensitive nature of financial data has led to prioritizing the risk of harmful data use. In return, the market provides hardly customized financial support but individuals keep autonomy and accountability of all their financial decisions. For some, accountability may promote learning and independence in decision making (Sunstein, 2015a, 2015b). Then, the benign character of the financial support is losing relevance.

Adding to autonomy concerns, the value of universally shared choice architectures has been highlighted (Mills, 2020). A new choice structure will likely be noticed if every individual experiences the change. In common experiences, individuals will exchange information and they can compare with others so that a sense of identity can emerge about how they deal with a choice. Conclusively, customization represents a trade-off between potential consumer welfare gains and possibly harming consumer autonomy.

\section{f. Disclosure of the intention to influence}

\section{Classification}

When it comes to defaults, disclosure means a default is transparent in a way that individuals recognize the intention to influence and how it is achieved (Hansen \& Jespersen, 2013; Bruns et al., 2018). Many defaults are transparent in the sense that they inform about the default option, what happens in the event of no choice, and whether individuals hold alternative options. With 'disclosure' we refer to an 
Table 6. Summary: observations on the effect of disclosure on default success and legitimacy

Default Success

- Making a default transparent can be perceived as intrusive to some and as a benign recommendation to others

- Transparent defaults lead to similar nudge success as non-transparent ones but must not influence the same type of consumers

Default Legitimacy

- Consumer autonomy: the risk of exploiting cognitive biases is reduced

- Consumer welfare: Possibly, transparent defaults are less likely to nudge consumers against their preferences

explicit statement (Loewenstein et al., 2015) to allow individuals to unmask why they face a specific choice architecture (Table 6).

\section{Empirical Findings}

Although most studies do not apply a transparent nudge, the topic has grown more salient in recent studies. In total, four studies have tested how transparent defaults change the effectiveness of the previously tested non-transparent defaults (Goswami \& Urminsky, 2016; Bruns et al., 2018; Paunov et al., 2019; Dranseika \& Piasecki, 2020). Researchers that apply transparent defaults seem aware of how they change the choice situation.

Some hypotheses have been put forward. Most importantly, some claim defaults work 'better in the dark' than with transparency, that is, defaults' effectiveness relies on the covert nature (Bruns et al., 2018; Paunov et al., 2019). Another reason for reduced nudge success could be that making a nudge transparent states the intention to guide an individual. Such nudges explicitly claim to know what is best for one which may lead to psychological reactance (Loewenstein et al., 2015; Bruns et al., 2018). In contrast, unmasking the default through framing presents an opportunity to persuade. For example, Bruns et al. (2018) present two types of transparency frames to ask for an $8 €$ donation: (1) 'Please consider that the preselected default value might have an influence on your decision'. (2) 'Please consider that the preselected default value is meant to encourage higher contributions for the climate protection fund'. Both transparent defaults raised the charity contributions from 1.82 to about 3 Euros per person, while a non-transparent default raised $2.95 €$ on average. The framing adds salience to the default option and can imply a social norm, particularly if the target behavior is not conflicting with previously learned moral mandates and is not perceived to serve the self-interests of the choice architect (Paunov et al. 2019). The majority of studies report similar nudge success for transparent defaults compared to non-transparent ones (Goswami \& Urminsky, 2016; Bruns et al., 2018; Dranseika \& Piasecki, 2020). At this stage, we agree with the observation by Loewenstein et al. (2015) that transparent nudges do not work less when individuals are explicitly informed that a default rule is in place.

\section{Ethical Implication}

In contrast to policy measures, such as explicit taxes, non-transparent defaults are rather 'hidden persuaders'. Nudged individuals may not be aware of the policy, 
raising autonomy concerns (Schubert, 2017; Bruns et al., 2018). Additionally, the covert nature of the default allows for exploitation of psychological biases which is less feasible with transparent nudges (Loewenstein et al., 2015). Transparent defaults can be a safeguard against the exploitation of biases through defaults. Nudges do not violate consumer autonomy if each nudge is, in principle, transparent, ensuring that everyone can unmask the manipulation if they wish (Smith et al., 2013).

The welfare perspective is less clear. The type of individuals influenced by a default may heavily depend on whether a default is unmasked or not. Even if the same number of individuals stick to a default option, a transparent default might be better equipped to protect individuals from being nudged against their self-interest. Research has started to address whether consumers that stick to a default would also prefer the default option in an active choice scenario (Ghesla et al., 2020), but the share of consumers ending up with their preferred option still has to be confirmed for transparent versus non-transparent defaults.

\section{Synthesis of the effect of taxonomic characteristics on default success and legitimacy}

To illustrate the effect of taxonomic characteristics, we qualitatively assessed previous observations. In case observations point toward improved consumer autonomy or welfare, we assign a plus ' + ' sign, two of them if both are improved and vice versa if these consumer concepts are harmed. In the same fashion, we describe unambiguous tendencies of a design feature to increase or decrease default success (Table 7).

(1) Although no reviewed default was ill-natured, not all defaults were convincingly argued to optimize welfare. The work of a choice architect is especially demanded if considerable welfare losses are associated with UDCs as status quo. Choice architects should identify such UDCs and address the welfare impact. If an intervention is deemed meaningful and the choice is rather characterized by automated decision-making patterns, then a DDC seems better equipped than an ACC to break undesirable habits.

(2) In some cases, individuals have the capacity to reflect on the choice at hand, then a forced active choice or default framing may produce similar behavioral change while providing greater respect to consumer autonomy. The combination of structuring the choice via default and describing the choice via default framing is promising to produce particularly strong nudge success without adding ethical concerns.

(3) Currently, nudge success is the dominant question of experiments. The psychological effect mechanism, how a default changes behavior, holds strong ethical implications but has rarely been empirically researched, despite frequent theoretical descriptions of the mechanisms.

(4) An environmentally integrated default might be preferred to influence particularly automatic or routinely executed behavior. However, such defaults can easily bypass the reflected decision-making system and if not endorsed, will be perceived as manipulative. 
Table 7. Default success and legitimacy by taxonomic characteristic

\begin{tabular}{|c|c|c|c|}
\hline Characteristic & Feature & $\begin{array}{l}\text { Default } \\
\text { Success }\end{array}$ & $\begin{array}{c}\text { Default } \\
\text { Legitimacy }\end{array}$ \\
\hline \multirow{3}{*}{$\begin{array}{l}\text { (1) Initial state of choice } \\
\text { architecture }\end{array}$} & Undesirable default (UDC) & 0 & 0 \\
\hline & Active choosing (ACC) & + & + \\
\hline & Desirable default (DDC) & ++ & 0 \\
\hline \multirow[t]{5}{*}{ (2) Invasiveness } & Costly opt-out & ++ & -- \\
\hline & Costless opt-out & 0 & 0 \\
\hline & Default framing & 0 & + \\
\hline & Costless opt-out and framing & + & + \\
\hline & Forced active choice & 0 & + \\
\hline \multirow{3}{*}{$\begin{array}{l}\text { (3) Psychological effect } \\
\text { mechanism }\end{array}$} & Inertia & $?$ & 0 \\
\hline & Implied endorsement & $?$ & - \\
\hline & Cognitive biases & $?$ & -- \\
\hline \multirow[t]{2}{*}{ (4) Visibility } & Interface (digital or analog) & 0 & 0 \\
\hline & Environmentally integrated & 0 & - \\
\hline \multirow[t]{2}{*}{ (5) Customization } & Mass default & 0 & 0 \\
\hline & Smart, Adaptive, Persistent & + & +- \\
\hline \multirow[t]{2}{*}{ (6) Disclosure } & Non-transparent & 0 & 0 \\
\hline & Transparent intention & 0 & ++ \\
\hline
\end{tabular}

The reference point for the evaluation is: (1) an initially undesirable default condition, (2) with costless opt-out, (3) with inertia as defined effect mechanism, (4) nudged through a text on an interface, (5) uniform (mass nudge) for all individuals, and (6) and non-transparent, ' + ' = increase, ' - ' $=$ decrease, ' ++ ' $=$ strong increase, ' -- ' $=$ strong decrease, $0=$ unclear direction of change, '?' = insufficient empirical evidence, ' +- ' $=$ enhanced consumer welfare and decreases consumer autonomy.

(5) Theoretically, a customized default is well equipped to enhance consumer welfare. The customization can accommodate individual heterogeneity but bears a significant risk to degrade the autonomy in decision making.

(6) To disclose the intent of a default provides greater respect to consumer autonomy. The default success does not seem to depend on the disclosure. We assume that a disclosed default will influence some individuals previously unaffected and the other way around, which may lead to more individuals implementing their reflected preferences.

Generally, more effective nudges are often perceived as less legitimate. We have discussed how the highly invasive costly opt-outs are particularly effective in changing behavior but threaten consumer welfare and autonomy. Such invasive nudges are also less publicly accepted (Sunstein \& Reisch, 2019). However, this relationship does not hold for all design options available. The combination of a default with default framing increases default success without harming legitimacy. Making the intent of a default transparent enhances consumer autonomy and may not harm 
default success. Replacing an undesirable default with an active choice will influence behavior and provides greater respect to consumer autonomy.

\section{Limitations}

Default success has to be interpreted with care. The studies reflect a broad literature concerning research domains, hypothetical and non-hypothetical experiments, online, lab, and field experiments, and different defaulting strategies. Our analysis focuses on variations of taxonomic characteristics within studies, ignoring a bulk of information, but avoiding unreasonable comparisons. As a result, only a limited number of studies back our interpretation of nudge success.

Future reviews should aim for quantitative estimations of nudge success concerning the taxonomic features. Quantitative effects across behavioral fields are difficult to predict (Szaszi et al., 2018), so a separate analysis for each field is advised.

The ethical evaluation neglects the perspective of decision-makers and focuses on the taxonomic characteristics that choice architects have control over. The taxonomic characteristics touch upon a wide spectrum of ethical concerns that we and other researchers have observed. Despite our best efforts, the assessment must not be fully comprehensive.

\section{Conclusions}

The review of the taxonomic characteristics provides guidance to researchers and policymakers applicable to the behavioral domains that defaults are applied in (Appendix Table A1). Intuitively, choice architects pursue behavioral change, however, to enter the policy arena, legitimacy should be the primary objective. Researchers can assist policymakers in designing ethically permissible defaults by making use of the taxonomic options that we present. In many circumstances, policymakers will find it appealing to introduce a behavioral policy intervention that promotes a behavior of social interest without threatening the concepts of consumer autonomy and welfare. Some of the discussed taxonomic changes will even improve default success or legitimacy, without trading off one for the other (Table 7).

Researchers have additional opportunities to pro-actively investigate arguments that may hinder a policy implementation. In some instances, theoretical concerns are not empirically substantiated. We recommend investigating (1) the visibility, that is, whether individuals recognize the decision, (2) vulnerable groups, for example, whether particularly lower-income groups are adversely affected, and (3) the psychological mechanism, that is, whether the default is indeed effective through cognitive biases.

Supplementary material. To view supplementary material for this article, please visit https://doi.org/10. 1017/bpp.2021.33.

Acknowledgments and Funding statement. The article was fully financed by the DFG funded project 'Key food choices and climate change' (project no. 431972934). The funding organization had no role in the research design nor in the decision to publish. The article would not have been possible without Henrike Sternberg, Dorothee Seybold, and Merindah Loessl, who skillfully supported the data collection. We thank Prof. Armando Perez-Cueto for discussing the research idea during the planning stage. Last but not least, we are grateful to the two anonymous reviewers that have greatly helped in sharpening the research contribution. 
Table A1 The reviewed studies by research domain, target behavior, type of control and treatment group, sub-studies, study type and country

\begin{tabular}{|c|c|c|c|c|c|c|c|c|}
\hline ID & Author & Domain & Target behavior & Treatment & Control & Sub & Study-type & Country \\
\hline 2 & (Briscese, 2019) & 0 & $\begin{array}{l}\text { charitable giving, charitable } \\
\text { re-lending }\end{array}$ & $A C C+D D C$ & UDC & 2 & Field experiment & AUS \\
\hline 3 & (Crow et al., 2019) & 0 & $\begin{array}{l}\text { charitable giving (at checkout } \\
\text { counter) }\end{array}$ & DDC & ACC & 1 & Online Experiment & USA \\
\hline 4 & $\begin{array}{l}\text { (Fosgaard and Piovesan, } \\
\text { 2015) }\end{array}$ & 0 & $\begin{array}{l}\text { charitable giving (public good } \\
\text { game) }\end{array}$ & DDC & UDC & 1 & Lab Experiment & DK \\
\hline 5 & (Ghesla et al., 2020) & 0 & charitable giving & DDC & $\mathrm{ACC}$ & 2 & Lab Experiment & SWI \\
\hline 6 & (Zarghamee et al., 2017) & 0 & Charitable giving & $\mathrm{DDC}$ & UDC & 1 & framed field experiment & USA \\
\hline 7 & (Schulz et al., 2018) & 0 & Charitable giving & DDC & $\mathrm{ACC}$ & 1 & Framed Experiment & SWI \\
\hline 8 & (Nelson et al., 2019) & 0 & $\begin{array}{l}\text { Charitable giving (on-site, for } \\
\text { coastal and marine } \\
\text { conservation) }\end{array}$ & DDC & $\mathrm{ACC}$ & 3 & Field experiment & IDN \\
\hline 11 & (Schneider et al., 2019) & @ & Selecting the elD & DDC & $\mathrm{ACC}$ & 2 & Online Experiment & USA \\
\hline 12 & (Dogruel et al., 2017) & @ & increase use of privacy settings & $A C C+D D C$ & UDC & 2 & Online Experiment & USA \\
\hline 13 & $\begin{array}{l}\text { (Dranseika and Piasecki, } \\
\text { 2020) }\end{array}$ & $@++$ & $\begin{array}{l}\text { increase consent to participate } \\
\text { in learning health care system }\end{array}$ & DDC & UDC & 2 & Lab experiment & UK \\
\hline
\end{tabular}




\begin{tabular}{|c|c|c|c|c|c|c|c|c|}
\hline 14 & $\begin{array}{l}\text { (Theotokis and } \\
\text { Manganari, 2015) }\end{array}$ & $@++$ & $\begin{array}{l}\text { Participation in e-statement } \\
\text { service, Participation in } \\
\text { e-bills, Increase towel reuse in } \\
\text { hotels }\end{array}$ & $A C C+D D C$ & UDC & 4 & $\begin{array}{r}\text { Lab and Field } \\
\text { experiment }\end{array}$ & ? \\
\hline 15 & $\begin{array}{l}\text { (Ang and Alexandrov, } \\
\text { 2017) }\end{array}$ & $\$$ & $\begin{array}{l}\text { Uptake of federal student loans } \\
\text { as opposed to private }\end{array}$ & DDC & UDC & 1 & Field experiment & USA \\
\hline 16 & (Hoffmann et al., 2019) & $\$$ & $\begin{array}{l}\text { increase socially responsible } \\
\text { investment (SRI) }\end{array}$ & $\mathrm{ACC}$ & UDC & 2 & Online Experiment & AUS \\
\hline 17 & $\begin{array}{l}\text { (Fonseca and Grimshaw, } \\
\text { 2017) }\end{array}$ & $\$$ & decrease tax non-compliance & DDC & $\mathrm{ACC}$ & 3 & Online Experiment & UK \\
\hline 18 & (Feltz, 2016) & $\$$ & $\begin{array}{l}\text { Improve surrogate financial } \\
\text { decisions (payment partially } \\
\text { invested in index fund, } \\
\text { annual payment) }\end{array}$ & DDC & $\mathrm{ACC}$ & 2 & Online Experiment & USA \\
\hline 19 & (Camilleri et al., 2019) & $\$$ & $\begin{array}{l}\text { Better retirement investments } \\
\text { choices (by "life cycle } \\
\text { model") }\end{array}$ & $A C C+D D C$ & UDC & 1 & Online Experiment & AUS \\
\hline 20 & (Brune et al., 2017) & $\$$ & $\begin{array}{l}\text { increase savings and reduce } \\
\text { (temptation) spending }\end{array}$ & DDC & UDC & 1 & Field experiment & MAL and ZIM \\
\hline 21 & (Haan and Linde, 2018) & $\$$ & $\begin{array}{l}\text { Better investment decisions } \\
\text { (maximizing payout) }\end{array}$ & DDC & UDC & 1 & Lab experiment & NL \\
\hline 22 & (Loeb et al., 2018) & \& & choose healthier lunch menu & DDC & UDC & 1 & Field experiment & USA \\
\hline 23 & (Friis et al., 2017) & \& & $\begin{array}{l}\text { increase vegetable intake } \\
\text { (healthier) }\end{array}$ & DDC & $\mathrm{ACC}$ & 1 & Lab experiment & DK \\
\hline 24 & (Broers et al., 2017) & \& & increase Salsify soup purchase & DDC & ACC & 1 & Field experiment & BEL \\
\hline 25 & $\begin{array}{l}\text { (Mikkelsen and Quinto } \\
\text { Romani, 2017) }\end{array}$ & \& & reduce butter consumption & DDC & $\mathrm{ACC}$ & 1 & Field experiment & DK \\
\hline 26 & $\begin{array}{l}\text { (Campbell-Arvai et al., } \\
\text { 2012) }\end{array}$ & ஓ & choose meat free meal & DDC & $\mathrm{ACC}$ & 2 & Lab experiment & USA \\
\hline
\end{tabular}


Table A1 (Continued.)

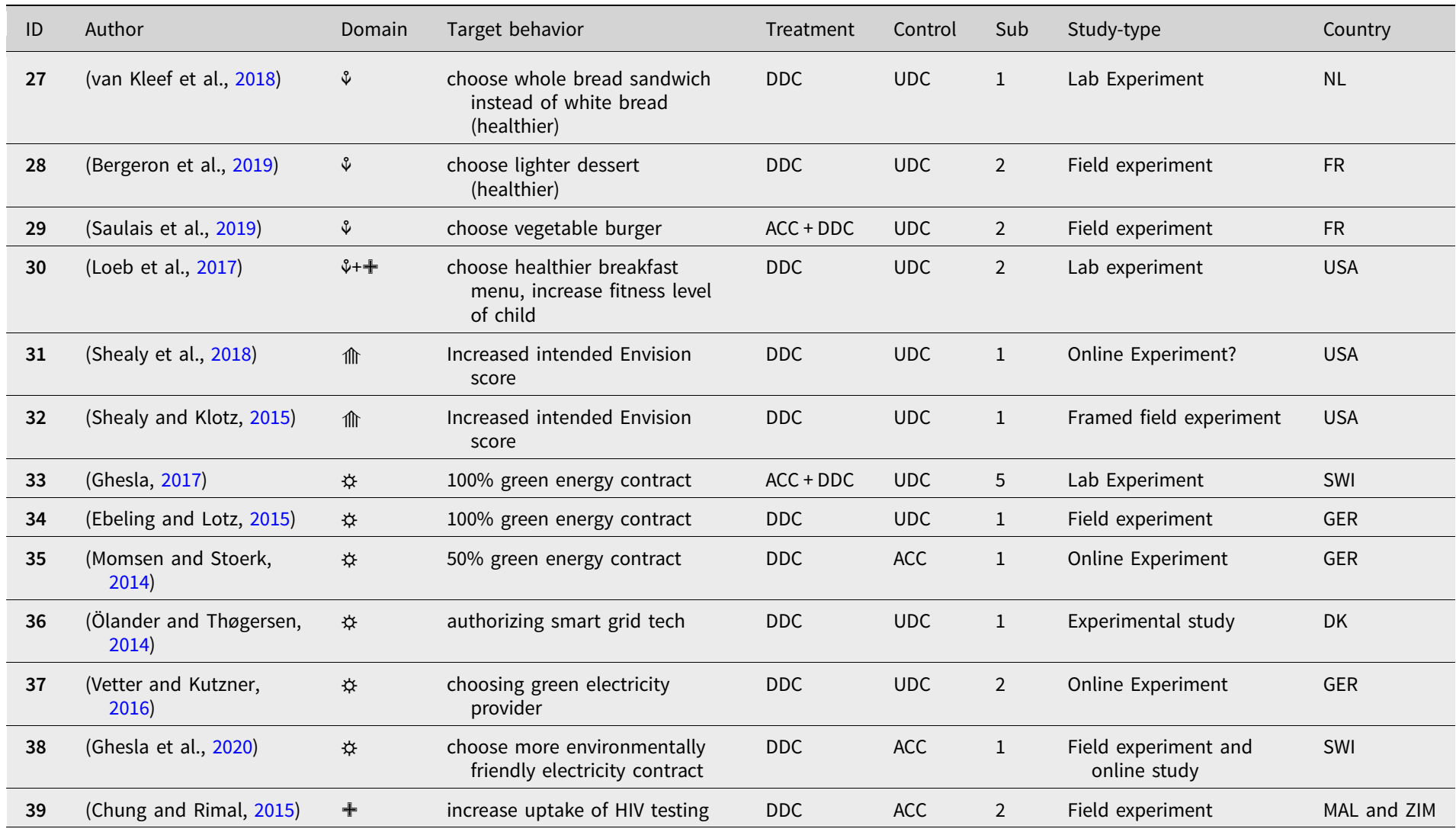




\begin{tabular}{|c|c|c|c|c|c|c|c|c|}
\hline 40 & (Beshears et al., 2021) & + & $\begin{array}{l}\text { encourage home delivery for } \\
\text { long-term prescription } \\
\text { medications }\end{array}$ & DDC & UDC & 1 & Field experiment & USA \\
\hline 41 & (Arvanitis et al., 2019) & + & $\begin{array}{l}\text { Enrollment to a specific Health } \\
\text { Insurance plan }\end{array}$ & DDC & $\mathrm{ACC}$ & 1 & Experimental study & GRE \\
\hline 42 & (Montoy et al., 2020) & + & Reduce Opioids prescriptions & DDC & $\mathrm{ACC}$ & 5 & Field experiment & USA \\
\hline 43 & (Lehmann et al., 2016) & + & $\begin{array}{l}\text { increase uptake of influenza } \\
\text { vaccination (among health } \\
\text { care workers) }\end{array}$ & DDC & UDC & 1 & Field experiment & NL \\
\hline 44 & (Soon et al., 2019) & + & $\begin{array}{l}\text { Decrease practitioner's choice } \\
\text { for low value care options }\end{array}$ & DDC & $\mathrm{ACC}$ & 1 & Online experiment & AUS \\
\hline 45 & (Malhotra et al., 2016) & + & $\begin{array}{l}\text { increase use of generic } \\
\text { (non-branded) medication }\end{array}$ & DDC & $\mathrm{ACC}$ & 1 & Field experiment & USA \\
\hline 46 & (Hsu et al., 2019) & + & Increase clinic transfer rates & DDC & UDC & 1 & Field experiment & TWN \\
\hline 47 & (Venema et al., 2018) & + & increase standing time at work & DDC & UDC & 1 & Field experiment & $\mathrm{NL}$ \\
\hline 48 & (Bourdeaux et al., 2016) & + & $\begin{array}{l}\text { improve medical ventilation } \\
\text { settings (low tidal volume } \\
\text { (Tve) standard) }\end{array}$ & DDC & UDC & 1 & Field experiment & UK \\
\hline 49 & $\begin{array}{l}\text { (Moseley and Stoker, } \\
\text { 2015) }\end{array}$ & + & $\begin{array}{l}\text { increase willingness to donate } \\
\text { organs }\end{array}$ & DDC & UDC & 1 & online experiment & UK \\
\hline 50 & (Probst et al., 2013) & + & $\begin{array}{c}\text { Increase number of relevant } \\
\text { laboratory tests ordered } \\
\text { (decrease irrelevant tests) }\end{array}$ & DDC & UDC & 2 & online experiment & USA \\
\hline 51 & $\begin{array}{l}\text { (Howard-Anderson et al., } \\
\text { 2020) }\end{array}$ & + & $\begin{array}{l}\text { reduce inappropriate (and total) } \\
\text { tests for Clostridioides } \\
\text { difficile infection }\end{array}$ & DDC & UDC & 2 & Field study & USA \\
\hline 52 & (Patel et al., 2017) & + & $\begin{array}{l}\text { increase influenza vaccination } \\
\text { rate }\end{array}$ & $\mathrm{ACC}$ & UDC & 1 & Field experiment & USA \\
\hline
\end{tabular}


Table A1 (Continued.)

\begin{tabular}{|c|c|c|c|c|c|c|c|c|}
\hline ID & Author & Domain & Target behavior & Treatment & Control & Sub & Study-type & Country \\
\hline 54 & (Bourdeaux et al., 2014) & + & $\begin{array}{l}\text { reduce use of Hydroxyethyl } \\
\text { starch, and increase use of } \\
\text { chlorhexidine mouthwash }\end{array}$ & $\mathrm{ACC}$ & UDC & 2 & Field experiment & UK \\
\hline 56 & $\begin{array}{l}\text { (Liebig and Rommel, } \\
\text { 2014) }\end{array}$ & Other & attach a sticker on the mailbox & DDC & $\mathrm{ACC}$ & 1 & Field experiment & GER \\
\hline 57 & $\begin{array}{l}\text { (Mazar and Hawkins, } \\
\text { 2015) }\end{array}$ & Other & reduce systematic cheating & $A C C+D D C$ & UDC & 1 & Lab Experiment & CAN \\
\hline 58 & (Paunov et al., 2019) & Other & $\begin{array}{l}\text { selecting a longer survey than } \\
\text { paid for }\end{array}$ & DDC & ACC & 4 & Online Experiment & UK \\
\hline 60 & (Kesternich et al., 2019) & $t$ & offset $\mathrm{CO} 2$ emissions for travel & $\mathrm{ACC}$ & UDC & 1 & Field experiment & GER \\
\hline 61 & $\begin{array}{l}\text { (Knezevic Cvelbar et al., } \\
\text { 2019) }\end{array}$ & $t$ & $\begin{array}{l}\text { reduce requests for room } \\
\text { cleaning in hotels }\end{array}$ & DDC & UDC & 1 & Field experiment & SVN \\
\hline
\end{tabular}

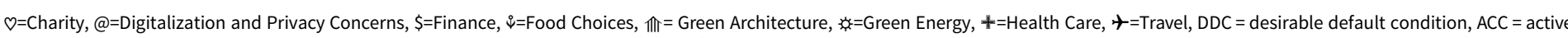
choice condition, UDC = undesirable default condition, Sub = number of sub-studies (many studies had more than one intervention but not necessarily a second default type intervention.

Sub-studies list only default interventions) 


\section{References}

Ang, X. and A. Alexandrov (2017), 'Choice architecture versus price: Comparing the effects of changes in the US student loan market', Journal of Empirical Legal Studies, 14(4): 762-812.

Arvanitis, A., K. Kalliris and K. Kaminiotis (2019), 'Are defaults supportive of autonomy? An examination of nudges under the lens of self-determination theory', The Social Science Journal, 1-11. https://doi.org/ 10.1016/j.soscij.2019.08.003.

Bergeron, S., M. Doyon, L. Saulais and J. Labrecque (2019), 'Using insights from behavioral economics to nudge individuals towards healthier choices when eating out: A restaurant experiment', Food Quality and Preference, 73: 56-64.

Beshears, J. and H. Kosowsky (2020), 'Nudging: Progress to date and future directions', Creating Habit Formation for Behaviors, 161(Suppl): 3-19. https://doi.org/10.1016/j.obhdp.2020.09.001.

Beshears, J., J. J. Choi, D. Laibson and B. C. Madrian (2021), 'Active choice, implicit defaults, and the incentive to choose', Organizational Behavior and Human Decision Processes, 163: 6-16. https://doi.org/10. 1016/j.obhdp.2019.02.001.

Blumenthal-Barby, J. S. and H. Burroughs (2012), 'Seeking better health care outcomes: The ethics of using the "nudge", The American Journal of Bioethics, 12(2): 1-10. https://doi.org/10.1080/15265161.2011. 634481.

Bourdeaux, C. P., K. J. Davies, M. J. C. Thomas, J. S. Bewley and T. H. Gould (2014), 'Using "nudge” principles for order set design: A before and after evaluation of an electronic prescribing template in critical care', BMJ Quality \& Safety, 23(5): 382-388.

Bourdeaux, C. P., M. J. C. Thomas, T. H. Gould, G. Malhotra, A. Jarvstad, T. Jones and I. D. Gilchrist (2016), 'Increasing compliance with low tidal volume ventilation in the ICU with two nudge-based interventions: Evaluation through intervention time-series analyses', BMJ Open, 6(5), https://doi.org/10.1136/ bmjopen-2015-010129.

Bovens, L. (2009), 'The ethics of nudge', in T. Grüne-Yanoff and S. O. Hansson (eds), Preference change: Approaches from philosophy, economics and psychology, Dordrecht: Springer Netherlands, 207-219. https://doi.org/10.1007/978-90-481-2593-7_10.

Briscese, G. (2019), 'Generous by default: A field experiment on designing defaults that align with past behaviour on charitable giving', Journal of Economic Psychology, 7), https://doi.org/10.1016/j.joep. 2019.06.010.

Broers, V. J. V., C. de Breucker, S. van den Broucke and O. Luminet (2017), 'A systematic review and meta-analysis of the effectiveness of nudging to increase fruit and vegetable choice', European Journal of Public Health, 27(5): 912-920.

Brune, L., X. Gine, J. Goldberg and D. Yang (2017), 'Savings defaults and payment delays for cash transfers: Field experimental evidence from Malawi', Journal of Development Economics, 129: 1-13.

Bruns, H., E. Kantorowicz-Reznichenko, K. Klement, M. L. Jonsson and B. Rahali (2018), 'Can nudges be transparent and yet effective?' Journal of Economic Psychology, 65: 41-59.

Camilleri, A. R., M.-A. Cam and R. Hoffmann (2019), 'Nudges and signposts: The effect of smart defaults and pictographic risk information on retirement saving investment choices', Journal of Behavioral Decision Making, 32(4): 431-449.

Campbell-Arvai, V., J. Arvai and L. Kalof (2012), 'Motivating sustainable food choices: The role of nudges, value orientation, and information provision', Environment and Behavior, 46(4): 453-475.

Chung, A. H. and R. N. Rimal (2015), 'Applying choice architecture principles to understand HIV testing: Findings from Malawi and Zimbabwe', AIDS Education and Prevention, 27(4): 362-372.

Crow, K., F. Mathmann and D. Greer (2019), 'Got a dollar? Locomotion orientation decreases the effect of defaults on charitable giving', Journal of Retailing and Consumer Services, 48: 1-6.

d'Adda, G., V. Capraro and M. Tavoni (2017), 'Push, don't nudge: Behavioral spillovers and policy instruments', Economics Letters, 154: 92-95.

Davidai, S., T. Gilovich and L. D. Ross (2012), 'The meaning of default options for potential organ donors', Proceedings of the National Academy of Sciences, 109(38): 15201-15205. https://doi.org/10.1073/pnas. 1211695109.

Dogruel, L., S. Joeckel and J. Vitak (2017), 'The valuation of privacy premium features for smartphone apps: The influence of defaults and expert recommendations', Computers in Human Behavior, 77: 230-239. 
Downs, S. H. and N. Black (1998), 'The feasibility of creating a checklist for the assessment of the methodological quality both of randomised and non-randomised studies of health care interventions', Journal of Epidemiology and Community Health, 52(6): 377-384. https://doi.org/10.1136/jech.52.6.377.

Dranseika, V. and J. Piasecki (2020), 'Transparent defaults and consent for participation in a learning health care system: An empirical study', Journal of Empirical Research on Human Research Ethics, 15(4): 261-270. https://doi.org/10.1177/1556264620904272.

Ebeling, F. and S. Lotz (2015), 'Domestic uptake of green energy promoted by opt-out tariffs', Nature Climate Change, 5(9): 868+.

Engelen, B. (2019), 'Ethical criteria for health-promoting nudges: A case-by-case analysis', The American Journal of Bioethics, 19(5): 48-59.

Feltz, A. (2016), 'Financial surrogate decision making: Lessons from applied experimental philosophy', Spanish Journal of Psychology, 19, https://doi.org/10.1017/sjp.2016.54.

Fonseca, M. A. and S. B. Grimshaw (2017), 'Do behavioral nudges in prepopulated tax forms affect compliance? Experimental evidence with real taxpayers', Journal of Public Policy \& Marketing, 36(2): 213-226.

Fosgaard, T. R. and M. Piovesan (2015), 'Nudge for (the public) good: How defaults can affect cooperation', PLOS ONE, 10(12).

Fracassi, C. and W. Magnuson (2021), 'Data autonomy', in F. Johnson (ed.), Vanderbilt law review. Vanderbilt Univ School of Law, Nashville, TN, USA: Vanderbilt Law Review, pp. 327-383.

Friis, R., L. R. Skov, A. Olsen, K. M. Appleton, L. Saulais, C. Dinnella, H. Hartwell, L. Depezay, E. Monteleone, A. Giboreau and F. J. A. Perez-Cueto (2017), 'Comparison of three nudge interventions (priming, default option, and perceived variety) to promote vegetable consumption in a self-service buffet setting', PLoS One, 12(5).

Ghesla, C. (2017), 'Defaults in green electricity markets: Preference match not guaranteed', Journal of the Association of Environmental and Resource Economists, 4(S1): S37-S84. https://doi.org/10.1086/691977.

Ghesla, C., M. Grieder and J. Schmitz (2019), 'Nudge for good? Choice defaults and spillover effects', Frontiers in Psychology, 10: 178. https://doi.org/doi.org/10.3389/fpsyg.2019.00178.

Ghesla, C., M. Grieder and R. Schubert (2020), 'Nudging the poor and the rich - A field study on the distributional effects of green electricity defaults', Energy Economics, 86: 104616. https://doi.org/10.1016/j. eneco.2019.104616.

Goldstein, D. G., E. J. Johnson, A. Herrmann and M. Heitmann (2008), 'Nudge your customers toward better choices', Harvard Business Review, 86(12): 99-105.

Goswami, I. and O. Urminsky (2016), 'When should the ask be a nudge? The effect of default amounts on charitable donations', Journal of Marketing Research, 53(5): 829-846.

Haan, T. de and J. Linde (2018), "Good nudge lullaby": Choice architecture and default bias reinforcement', Economic Journal, 128(610): 1180-1206.

Hansen, P. G. and A. M. Jespersen (2013), 'Nudge and the manipulation of choice: A framework for the responsible use of the nudge approach to behaviour change in public policy', European Journal of Risk Regulation, 4(1): 3-28. Cambridge Core. https://doi.org/10.1017/S1867299X00002762.

Heilmann, C. (2014), 'Success conditions for nudges: A methodological critique of libertarian paternalism', European Journal for Philosophy of Science, 4(1): 75-94.

Hoffmann, R., M.-A. Cam and A. R. Camilleri (2019), 'Deciding to invest responsibly: Choice architecture and demographics in an incentivised retirement savings experiment', Journal of Behavioral and Experimental Economics, 80: 219-230.

Howard-Anderson, J. R., M. E. Sexton, C. Robichaux, Z. Wiley, J. B. Varkey, S. Suchindran, B. Albrecht, K. Ashley Jones, S. K. Fridkin and J. T. Jacob (2020), 'The impact of an electronic medical record nudge on reducing testing for hospital-onset Clostridioides difficile infection', Infection Control \& Hospital Epidemiology, 41(4): 411-417.

Hsu, C.-M., L.-L. Liang, Y.-T. Chang and W.-C. Juang (2019), 'Emergency department overcrowding: Quality improvement in a Taiwan medical center', Journal of the Formosan Medical Association, 118 (1-part1): 186-193. https://doi.org/10.1016/j.jfma.2018.03.008.

Hummel, D. and A. Maedche (2019), 'How effective is nudging? A quantitative review on the effect sizes and limits of empirical nudging studies', Journal of Behavioral and Experimental Economics, 80: 47-58.

Jachimowicz, S. D., E. U. Weber and E. J. Johnson (2019), 'When and why defaults influence decisions: A meta-analysis of default effects', Behavioural Public Policy, 3(2): 159-186. https://doi.org/10.1017/bpp.2018.43. 
Johnson, E. J., S. B. Shu, B. G. C. Dellaert, C. Fox, D. G. Goldstein, G. Häubl, R. P. Larrick, J. W. Payne, E. Peters, D. Schkade, B. Wansink and E. U. Weber (2012), 'Beyond nudges: Tools of a choice architecture', Marketing Letters, 23(2): 487-504. https://doi.org/10.1007/s11002-012-9186-1.

Jung, J. Y. and B. A. Mellers (2016), 'American attitudes toward nudges', Judgment \& Decision Making, 11(1): $62-74$.

Kaiser, M., M. Bernauer, C. R. Sunstein and L. A. Reisch (2020), 'The power of green defaults: The impact of regional variation of opt-out tariffs on green energy demand in Germany', Ecological Economics, 174 (August): 106685. https://doi.org/10.1016/j.ecolecon.2020.106685.

Keller, P., B. A. Harlam, G. Loewenstein and K. G. M. Volpp (2011), 'Enhanced active choice: A new method to motivate behavior change', Journal of Consumer Psychology, 21: 376-383.

Kesternich, M., D. Roemer and F. Flues (2019), 'The power of active choice: Field experimental evidence on repeated contribution decisions to a carbon offsetting program', European Economic Review, 114: 76-91.

Knezevic Cvelbar, L., B. Grün and S. Dolnicar (2019), “To clean or not to clean?" Reducing daily routine hotel room cleaning by letting tourists answer this question for themselves', Journal of Travel Research, 60(1): 220-229. https://doi.org/10.1177/0047287519879779.

Lehmann, B. A., G. B. Chapman, F. M. E. Franssen, G. Kok and R. A. C. Ruiter (2016), 'Changing the default to promote influenza vaccination among health care workers', Vaccine, 34(11): 1389-1392.

Liebig, G. and J. Rommel (2014), 'Active and forced choice for overcoming status quo bias: A field experiment on the adoption of "no junk mail" stickers in Berlin, Germany', Journal of Consumer Policy, 37(3): 423-435.

Loeb, K. L., C. Radnitz, K. Keller, M. B. Schwartz, S. Marcus, R. N. Pierson, M. Shannon and D. DeLaurentis (2017), 'The application of defaults to optimize parents' health-based choices for children', Appetite, 113: 368-375.

Loeb, K. L., C. Radnitz, K. L. Keller, M. B. Schwartz, N. Zucker, S. Marcus, R. N. Pierson, M. Shannon and D. DeLaurentis (2018), 'The application of optimal defaults to improve elementary school lunch selections: Proof of concept', The Journal of School Health, 88(4): 265-271. https://doi.org/10.1111/josh.12611.

Loewenstein, G., C. Bryce, D. Hagmann and S. Rajpal (2015), 'Warning: You are about to be nudged', Behavioral Science \& Policy, 1(1): 35-42.

Löfgren, Å. and K. Nordblom (2020), 'A theoretical framework of decision making explaining the mechanisms of nudging', Journal of Economic Behavior \& Organization, 174: 1-12.

Löfgren, Å., P. Martinsson, M. Hennlock and T. Sterner (2012), 'Are experienced people affected by a preset default option-Results from a field experiment', Journal of Environmental Economics and Management, 63(1): 66-72.

MacKay, D. and A. Robinson (2016), 'The ethics of organ donor registration policies: Nudges and respect for autonomy', The American Journal of Bioethics, 16(11): 3-12.

Malhotra, S., A. D. Cheriff, J. Travis Gossey, C. L. Cole, R. Kaushal and J. S. Ancker (2016), 'Effects of an E-prescribing interface redesign on rates of generic drug prescribing: Exploiting default options', Journal of the American Medical Informatics Association, 23(5): 891-898.

Mazar, N. and S. A. Hawkins (2015), 'Choice architecture in conflicts of interest: Defaults as physical and psychological barriers to (dis)honesty', Journal of Experimental Social Psychology, 59: 113-117.

McGill, R., E. Anwar, L. Orton, H. Bromley, F. Lloyd-Williams, M. O’Flaherty, D. Taylor-Robinson, M. Guzman-Castillo, D. Gillespie, P. Moreira, K. Allen, L. Hyseni, N. Calder, M. Petticrew, M. White, M. Whitehead and S. Capewell (2015), 'Are interventions to promote healthy eating equally effective for all? Systematic review of socioeconomic inequalities in impact', BMC Public Health, 15(1): 457. https://doi.org/10.1186/s12889-015-1781-7.

McKenzie, C. R. M., M. J. Liersch and S. R. Finkelstein (2006), 'Recommendations implicit in policy defaults', Psychological Science, 17(5): 414-420.

Michie, S., M. M. van Stralen and R. West (2011), 'The behaviour change wheel: A new method for characterising and designing behaviour change interventions', Implementation Science: IS, 6(42), https://doi. org/10.1186/1748-5908-6-42.

Mikkelsen, B. E. and A. Q. Romani (2017), 'Does buffet choice architecture affect intake? The effect of relocating butter at a breakfast buffet on food intake', Journal of Foodservice Business Research, 20(4): 489-496.

Mills, S. (2020), 'Personalized nudging', Behavioural Public Policy, 1-10. Cambridge Core. https:/doi.org/ 10.1017/bpp.2020.7. 
Momsen, K. and T. Stoerk (2014), 'From intention to action: Can nudges help consumers to choose renewable energy?' Energy Policy, 74: 376-382.

Montoy, J. C. C., Z. Coralic, A. A. Herring, E. J. Clattenburg and M. C. Raven (2020), 'Association of default electronic medical record settings with health care professional patterns of opioid prescribing in emergency departments: A randomized quality improvement study', JAMA Internal Medicine, 180(4): 487-493.

Moseley, A. and G. Stoker (2015), 'Putting public policy defaults to the test: The case of organ donor registration', International Public Management Journal, 18(2), SI: 246-264.

Münscher, R., M. Vetter and T. Scheuerle (2016), 'A review and taxonomy of choice architecture techniques', Journal of Behavioral Decision Making, 29(5): 511-524.

Nelson, K. M., S. Partelow and A. Schlueter (2019), 'Nudging tourists to donate for conservation: Experimental evidence on soliciting voluntary contributions for coastal management', Journal of Environmental Management, 237: 30-43.

Ölander, F. and J. Thøgersen (2014), 'Informing versus nudging in environmental policy', Journal of Consumer Policy, 37(3): 341-356.

O’Reilly-Shah, V. N., G. S. Easton, C. S. Jabaley and G. C. Lynde (2018), 'Variable effectiveness of stepwise implementation of nudge-type interventions to improve provider compliance with intraoperative low tidal volume ventilation', BMJ Quality \& Safety, 27(12): 1008-1018.

Patel, M. S., K. G. Volpp, D. S. Small, C. Wynn, J. Zhu, L. Yang, S. J. Honeywell and S. C. Day (2016), 'Using active choice within the electronic health record to increase physician ordering and patient completion of high-value cancer screening tests', Healthcare (Amsterdam, Netherlands), 4(4): 340-345. https://doi. org/10.1016/j.hjdsi.2016.04.005.

Patel, M. S., K. G. Volpp, D. S. Small, C. Wynne, J. Zhu, L. Yang, S. J. Honeywell and S. C. Day (2017), 'Using active choice within the electronic health record to increase influenza vaccination rates', Journal of General Internal Medicine, 32(7): 790-795. https://doi.org/10.1007/s11606-017-4046-6.

Paunov, Y., M. Wänke and T. Vogel (2019), 'Ethical defaults: Which transparency components can increase the effectiveness of default nudges?' Social Influence, 14(3-4): 104-116.

Probst, C. A., V. A. Shaffer and Y. Raymond Chan (2013), 'The effect of defaults in an electronic health record on laboratory test ordering practices for pediatric patients', Health Psychology, 32(9), SI: 9951002.

Reisch, L. A. (2020), 'Nudging hell und dunkel: Regeln für digitales nudging', Wirtschaftsdienst, 100(2): 8791. https://doi.org/10.1007/s10273-020-2573-y.

Saulais, L., C. Massey, F. J. A. Perez-Cueto, K. M. Appleton, C. Dinnella, E. Monteleone, L. Depezay, H. Hartwell and A. Giboreau (2019), 'When are "dish of the day" nudges most effective to increase vegetable selection?' Food Policy, 85: 15-27.

Schneider, D., J. Klumpe, M. Adam and A. Benlian (2019), 'Nudging users into digital service solutions', Electronic Markets, 30: 863-881.

Schubert, C. (2017), 'Green nudges: Do they work? Are they ethical?’ Ecological Economics, 132: 329-342.

Schulz, J. F., P. Thiemann and C. Thoni (2018), 'Nudging generosity: Choice architecture and cognitive factors in charitable giving', Journal of Behavioral and Experimental Economics, 74: 139-145.

Shealy, T. and L. Klotz (2015), 'Well-endowed rating systems: How modified defaults can lead to more sustainable performance', Journal of Construction Engineering and Management, 141(10), https://doi.org/ 10.1061/(ASCE)CO.1943-7862.0001009.

Shealy, T., E. Johnson, E. Weber, L. Klotz, S. Applegate, D. Ismael and R. G. Bell (2018), 'Providing descriptive norms during engineering design can encourage more sustainable infrastructure', Sustainable Cities and Society, 40: 182-188.

Smith, N. C., D. G. Goldstein and E. J. Johnson (2013), 'Choice without awareness: Ethical and policy implications of defaults', Journal of Public Policy \& Marketing, 32(2): 159-172. https://doi.org/10. 1509/jppm.10.114.

Soon, J., A. C. Traeger, A. G. Elshaug, E. Cvejic, C. G. Maher, J. A. Doust, S. Mathieson, K. McCaffery and C. Bonner (2019), 'Effect of two behavioural "nudging" interventions on management decisions for low back pain: A randomised vignette-based study in general practitioners', BMJ Quality \& Safety, 28(7): 547-555.

Stryja, C. and G. Satzger (2019), 'Digital nudging to overcome cognitive resistance in innovation adoption decisions', The Service Industries Journal, 39(15-16): 1123-1139. 
Sunstein, C. R. (2013), 'The Storrs lectures: Behavioral economics and paternalism', Yale Law Journal, 122: 1826. http://dx.doi.org/10.2139/ssrn.2182619.

Sunstein, C. R. (2015a), 'Active choosing or default rules?: The policymaker's dilemma', Behavioral Science \& Policy, 1(1): 29-33.

Sunstein, C. R. (2015b), Choosing not to choose: Understanding the value of choice. New York: Oxford University Press. Retrieved from: https://books.google.de/books?id=EuEyBgAAQBAJ.

Sunstein, C. R. and L. A. Reisch (2014), 'Automatically green: Behavioral economics and environmental protection', Harvard Environmental Law Review, 38(1): 127. http://dx.doi.org/10.2139/ssrn.2245657.

Sunstein, C. R. and L. A. Reisch (2016), 'Behaviorally green: Why, which and when defaults can help', in F. Beckenbach, and W. Kahlenborn (eds), New perspectives for environmental policies through behavioral economics, Switzerland: Springer, 161-194.

Sunstein, C. R. and L. A. Reisch (2019), Trusting nudges: Toward a bill of rights for nudging. Abingdon, UK: Routledge.

Szaszi, B., A. Palinkas, B. Palfi, A. Szollosi and B. Aczel (2018), 'A systematic scoping review of the choice architecture movement: Toward understanding when and why nudges work', Journal of Behavioral Decision Making, 31(3): 355-366. https://doi.org/10.1002/bdm.2035.

Thaler, R. H. and C. R. Sunstein (2008), Nudge: Improving decisions about health, wealth, and happiness. London, UK: Yale University Press. Retrieved from: https://books.google.de/books?id=dSJQn8egXvUC.

Thaler, R. H. and W. Tucker (2013), 'Smarter information, smarter consumers', Harvard Business Review, 91(1): 44-54.

Theotokis, A. and E. Manganari (2015), 'The impact of choice architecture on sustainable consumer behavior: The role of guilt', Journal of Business Ethics, 131(2): 423-437.

van Kleef, E., K. Seijdell, M. H. Vingerhoeds, R. A. de Wijk and H. C. M. van Trijp (2018), 'The effect of a default-based nudge on the choice of whole wheat bread', Appetite, 121: 179-185.

Venema, T. A. G., F. M. Kroese and D. T. D. De Ridder (2018), 'I'm still standing: A longitudinal study on the effect of a default nudge', Psychology \& Health, 33(5): 669-681.

Vetter, M. and F. Kutzner (2016), 'Nudge me if you can-how defaults and attitude strength interact to change behavior', Comprehensive Results in Social Psychology, 1(1-3): 8-34.

Von Bergen, C. W. and M. P. Miles (2015), 'Social negative option marketing', Journal of Social Marketing, 5(2): 125-138. https://doi.org/10.1108/JSOCM-06-2014-0036.

Vugts, A., M. Van den Hoven, E. De Vet and M. Verweij (2020), 'How autonomy is understood in discussions on the ethics of nudging', Behavioural Public Policy, 4(1): 108-123. https://doi.org/10.1017/bpp. 2018.5.

Wansink, B. and D. R. Just (2016), 'The limits of defaults: Why French fries trump apple slices', BMC Research Notes, 9(1): 263.

Wansink, B. and J. Sobal (2007), 'Mindless eating: The 200 daily food decisions we overlook', Environment and Behavior, 39(1): 106-123. https://doi.org/10.1177/0013916506295573.

Whyte, K. P., E. Selinger, A. L. Caplan and J. Sadowski (2012), 'Nudge, nudge or shove, shove-The right way for nudges to increase the supply of donated cadaver organs', The American Journal of Bioethics, 12 (2): $32-39$.

$\mathrm{Wu}, \mathrm{X}$. and L. Jin (2020), 'Nudging: The unexpected impact on observers' inference of donors' prosocial behavior', Social Behavior and Personality: An International Journal, 48(1): 1-8.

Zarghamee, H. S., K. D. Messer, J. R. Fooks, W. D. Schulze, S. Wu and J. Yan (2017), 'Nudging charitable giving: Three field experiments', Journal of Behavioral and Experimental Economics, 66(SI): 137-149.

Zlatev, J. J., D. P. Daniels, H. Kim and M. A. Neale (2017), 'Default neglect in attempts at social influence', Proceedings of the National Academy of Sciences, 114(52): 13643-13648. https://doi.org/10.1073/pnas. 1712757114 .

Cite this article: Lemken D (2021). Options to design more ethical and still successful default nudges: a review and recommendations. Behavioural Public Policy 1-33. https://doi.org/10.1017/bpp.2021.33 